\title{
Reliability Assessment of 2400 MWth Gas-Cooled Fast Reactor Natural Circulation Decay Heat Removal in Pressurized Situations
}

\author{
C. Bassi and M. Marques \\ Commissariat à l'Energie Atomique, CEA Cadarache, DER/SESI, 13108 Saint-Paul-les-Durance, Cedex, France
}

Correspondence should be addressed to C. Bassi, christophe.bassi@cea.fr

Received 31 August 2007; Accepted 3 January 2008

Recommended by John Cleveland

\begin{abstract}
As the 2400 MWth gas-cooled fast reactor concept makes use of passive safety features in combination with active safety systems, the question of natural circulation decay heat removal (NCDHR) reliability and performance assessment into the ongoing probabilistic safety assessment in support to the reactor design, named "probabilistic engineering assessment" (PEA), constitutes a challenge. Within the 5th Framework Program for Research and Development (FPRD) of the European Community, a methodology has been developed to evaluate the reliability of passive systems characterized by a moving fluid and whose operation is based on physical principles, such as the natural circulation. This reliability method for passive systems (RMPSs) is based on uncertainties propagation into thermal-hydraulic (T-H) calculations. The aim of this exercise is finally to determine the performance reliability of the DHR system operating in a "passive" mode, taking into account the uncertainties of parameters retained for thermal-hydraulical calculations performed with the CATHARE 2 code. According to the PEA preliminary results, exhibiting the weight of pressurized scenarios (i.e., with intact primary circuit boundary) for the core damage frequency (CDF), the RMPS exercise is first focusing on the NCDHR performance at these T-H conditions.
\end{abstract}

Copyright ( $) 2008$ C. Bassi and M. Marques. This is an open access article distributed under the Creative Commons Attribution License, which permits unrestricted use, distribution, and reproduction in any medium, provided the original work is properly cited.

\section{INTRODUCTION}

The trend for safety demonstration of new reactor concepts is, nowadays, based on the combined application of deterministic and probabilistic tools (i.e., "risk-informed design guidance" [1]). In general, the main benefits of the use of probabilistic safety assessment (PSA) are to provide a risk measurement, which is useful to improve the concept. It is performed through the identification of plant vulnerabilities, of intersystem dependencies, and of potential common cause failures (CCFs). During conceptual design studies, the probabilistic engineering assessment (PEA), a simplified PSA in support of the design, provides useful insights about the examination of risk benefits from different design options and helps designers to improve the concept from safety and economical points of view. Finally, it anticipates design justifications during the licensing process and the deterministic safety demonstration.
The gas-cooled fast reactor is considered as a promising concept and has a high priority in CEA R\&D work program on future nuclear energy systems $[2,3]$. The main specifications of the 2400 MWth GFR concept are driven by the internationally agreed Generation IV objectives, which have been "translated" into the main features of the concept:

(i) a fast neutron core with a zero breeding gain (without fertile blankets) and characterized by an initial plutonium inventory allowing for the deployment of a GFR fleet near 2040 (sustainability and proliferation resistance concerns);

(ii) a helium-cooled primary circuit $\left(7 \mathrm{MPa}, 850^{\circ} \mathrm{C}\right.$ at core outlet) connected to a Brayton secondary circuit allowing for a high-thermodynamic efficiency (economics concern);

(iii) a decay heat removal (DHR) system based on dedicated loops allowing for forced or natural circulation (safety concern). 
According to the strategy proposed by the GFR design team [4], the natural circulation (NC) of gas, through the (DHR) system (dedicated loops for forced or natural circulation of gas, with passive water-filled secondary circuit) is foreseen:

(i) for pressurized situations (i.e., with intact helium pressure boundary);

(ii) for the transient termination (here called "late phase," starting around one day after the initiating event) of depressurized situations.

For the later, owing to the poor NC capability of gaseous coolant, a pressure level, evaluated at around $1.0 \mathrm{MPa}$ and provided by a closed-guard containment, should be maintained to guarantee that the temperatures in the core vessel are kept at acceptable values.

As the GFR reactor concept makes use of passive safety features in combination with active safety systems, the question of natural circulation decay heat removal (NCDHR) reliability and performance assessment into the ongoing PEA constitutes a challenge. Within the 5th Framework Program for Research and Development (FPRD), a methodology has been developed to evaluate the reliability of passive systems characterized by a moving fluid and whose operation is based on physical principles, such as the natural circulation. This reliability method for passive systems (RMPSs) [5] is based, in particular, on uncertainties propagation into thermalhydraulic (T-H) calculations. The aim of this RMPS exercise is finally to determine the performance reliability of the DHR system operating in a "passive" mode, taking into account the uncertainties of parameters retained for T-H calculations (distributions attached to critical parameters and uncertainties propagation). According to the PEA preliminary results, exhibiting the importance of pressurized scenarios (i.e., with intact primary circuit boundary) for the core damage frequency (see Section 2), the RMPS exercise is first focusing on the NCDHR perfomance at high-primary pressure and decay heat. At this point, some publications which discuss this topic, for depressurized scenarios, are referred in $[6,7]$.

\section{THE GFR DECAY HEAT REMOVAL STRATEGY}

The DHR system has a strong impact on the overall reactor architecture. On the contrary with other gas-cooled reactor concepts (like high-temperature reactors), solutions based on core thermal inertia plus conduction and radiation to remove heat were not applicable to the GFR due to the high core power density $\left(100 \mathrm{MW} / \mathrm{m}^{3}\right.$ compared to $5-10 \mathrm{MW} / \mathrm{m}^{3}$ in HTRs). Therefore, the decision was taken to study with more details systems relying on helium circulation, based on natural circulation as far as possible. This explains some design criteria and options:

(i) an upward core cooling flow and a location of the exchangers (DHR and IHX) above the core level;

(ii) a core design criterion based on a low-pressure drop (which eases the He circulation);

(iii) the use of a guard containment in order to limit the loss of pressure (sufficient backup pressure) after a primary circuit depressurization;

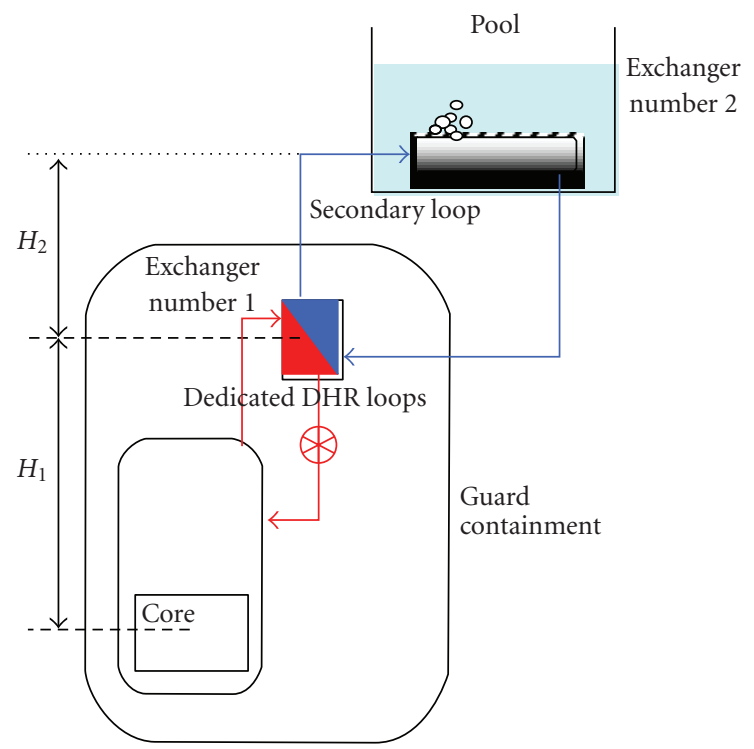

FIGURE 1: Schematic of the DHR system.

(iv) the use of dedicated DHR loops, allowing to increase the difference of elevation between the DHR heat exchanger and the core, as shown in Figure 1. If needed, the primary DHR circuit can operate with a blower, generating a forced circulation in addition to the natural circulation;

(v) the use of three loops $(3 \times 100 \%$ redundancy $)$ assuming that one could be lost due to the accident initiating event (e.g., break) and that another one must be supposed unavailable (single-failure criterion).

The strategy for the depressurization/backup pressure of the GFR 2400 MWth has been decided already. The most attractive option is the "medium" backup pressure strategy: the pressure is kept "high enough" in order to obtain sufficient margin and to significantly ease the safety demonstration. In fact, for laminar flow conditions and for a given mass flow, the pumping power is almost inversely proportional to the square of the gas pressure, this means that the pumping power decreases very significantly when the pressure increases. At $1.0 \mathrm{MPa}$, about 15 to $20 \mathrm{~kW}$ are required few minutes after the reactor SCRAM instead of more than $1 \mathrm{MW}$ at $0.1 \mathrm{MPa}$. In addition, for scenarios characterized by a loss of primary circuit integrity (e.g., LOCA), keeping some "backup" pressure at $1.0 \mathrm{MPa}$ allows the possibility to use natural circulation after some time delay (typically 24 hours) due to the decay heat decrease. Finally, such medium backup pressure could be coherent with the use of a metallic containment, also simpler and smaller systems could be used thus limiting investment, operation, and maintenance costs.

Therefore, the DHR system consists of the following:

(i) a metallic guard containment enclosing the primary system, not pressurized in normal operation, and having a free volume such as the fast primary helium expansion is leading to an equilibrium pressure of 1.0 MPa; 


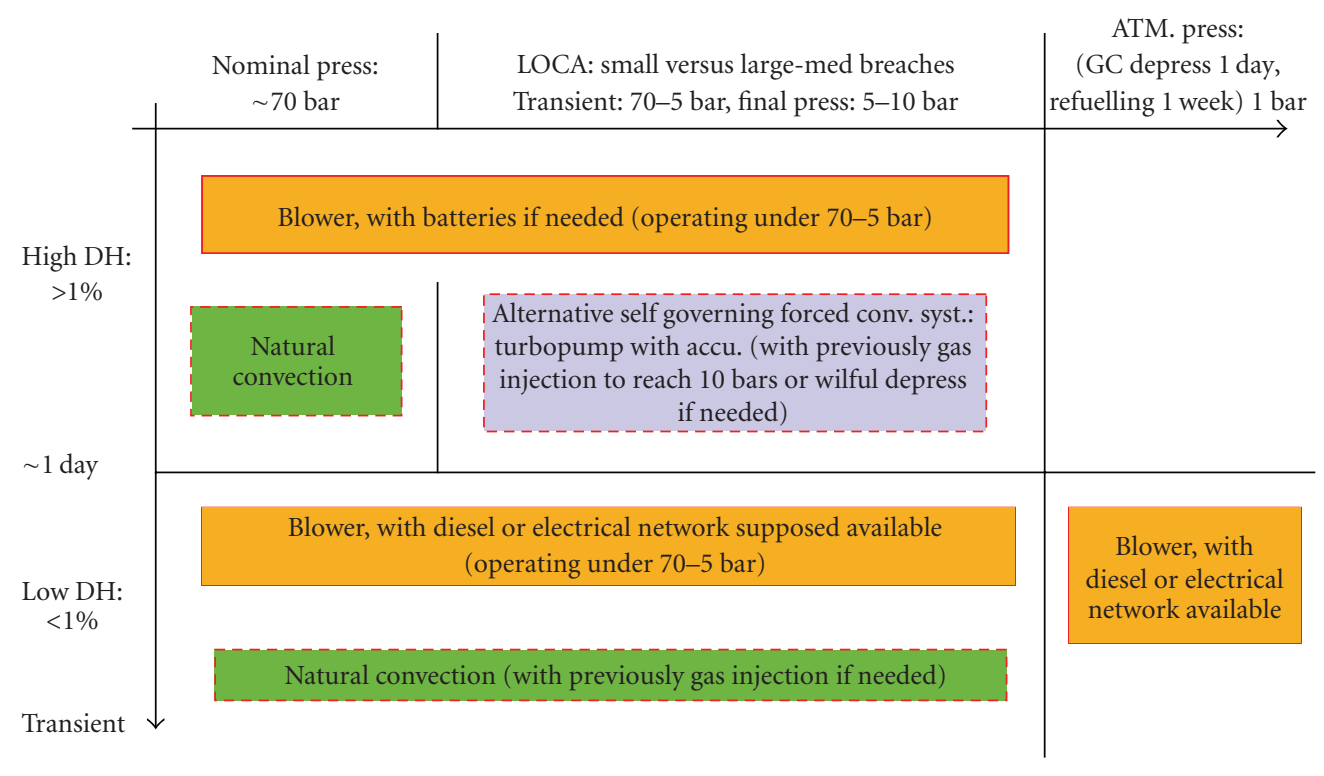

Various operation modes:

Current systems specifications: (primary)

- Normal system

- - - Backup system (necessity to be confirmed)

FIgURE 2: Schematic of the DHR strategy based on mixed natural and forced mechanisms [4].

(ii) three dedicated DHR loops (redundancy) with secondary loops connected to an external water pool (the ultimate heat sink).

This strategy and the means (systems, phenomena) to achieve their intended mission are depicted in Figure 2.

\section{SOURCES OF UNCERTAINTIES IN THE GFR PROBABILISTIC ENGINEERING ASSESSMENT [8]}

Until now, a focus is held in the PEA on the two first families (loss of coolant accidents and loss of offsite power) in order to check the consistency of the DHR systems layout (two DHR loops operating in a "dual" circulation scheme: forced circulations (FCs) and natural circulations, and two DHR loops for forced circulation only and designed according to the systems diversification principle). The choice of these two families is driven by the aforementioned DHR strategy (see Section 2) depending on the primary circuit integrity status (LOCAs are representative of depressurized situations and LOOP of pressurized ones). In Figure 3 is reported the event tree for the LOOP initiating event.

It seems important to notice that the two time periods are distinguished according to the systems or mechanisms potentially involved for DHR ("early phase" during the first 24 hours, and "late phase" from 24 to 168 hours). Many reasons have led to this choice: the first is design dependant (batteries or DHR ternary pools autonomy, systems or mechanisms involved during the two time periods), and the second is relative to some deterministic practices leading to combine some "frequent IEs" with short-duration LOOP or blackout. Therefore, this PEA will furnish some relevant results for the design basis events classification. An iterative process through sensitivity studies (importance measures assessment, sensitivity indices) and cost-benefit evaluation (systems redundancy level) would finally help to optimize the concept without safety weakening.

Usually, uncertainties are categorized as "aleatory" (i.e., inability to predict random observable events) or as epistemic [9] (i.e., our confidence in the knowledge of a model or in some data). These epistemic uncertainties are roughly related to the input parameters, the structure of the model, and finally to its completeness.

For input parameters, lognormal probability distribution functions are systematically attached to components-failure rates, with error factor (i.e., the square root of the 95 to 5 percentile ratio) set to the following:

(i) three for components with operational feedback (e.g., water circuits);

(ii) ten for components in a gaseous environment (e.g,. blowers, valves, etc.).

The uncertainty propagation is performed thanks to the Risk Spectrum [10] software.

Modeluncertainties are studied through parametric studies to analyze the effects of simplifying assumptions on the model output (core bypass assumption weight, e.g., in GFR PEA). 


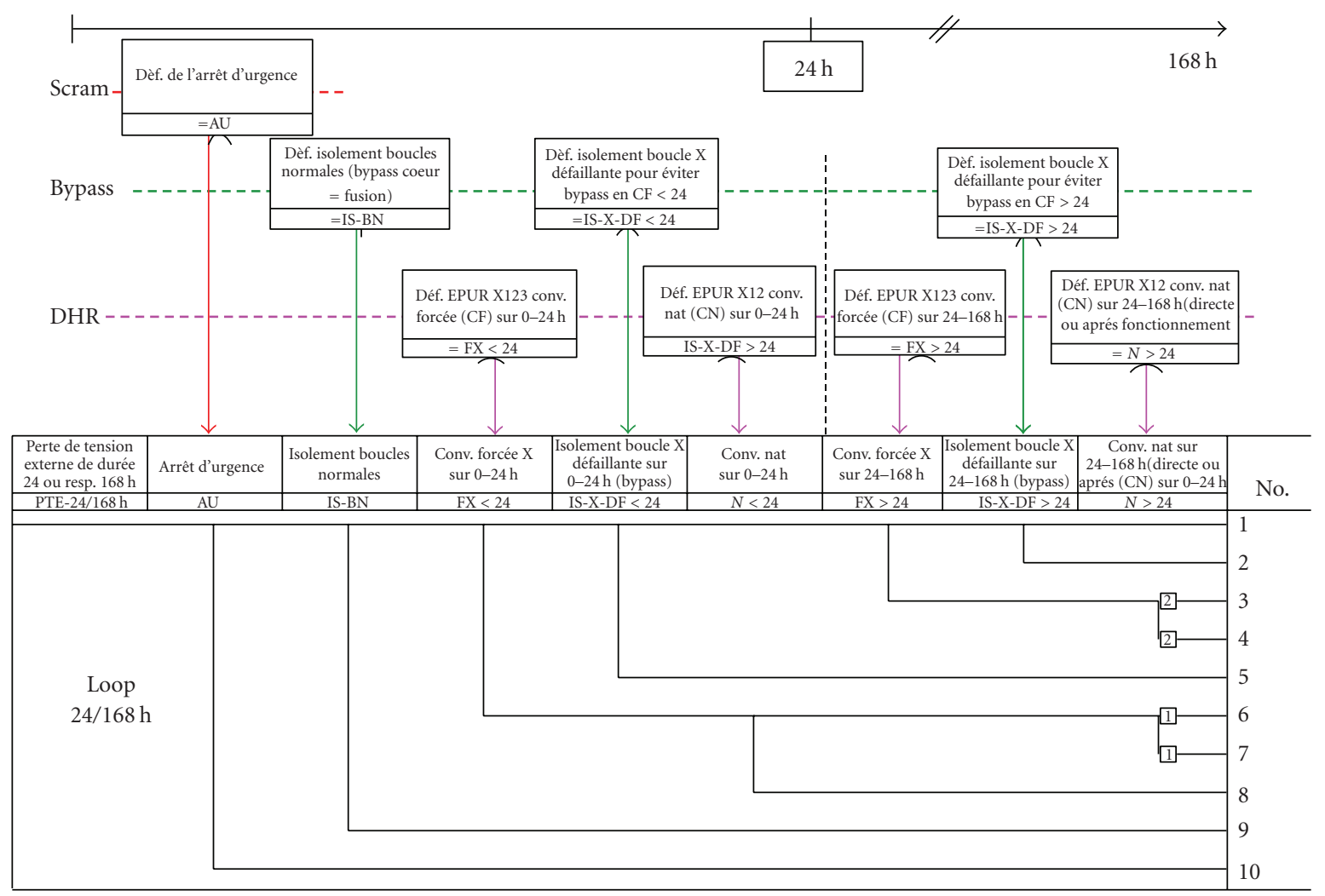

FIGURE 3: Event tree for LOOP IE (representative of the pressurized situation) in GFR PEA.

Regarding the uncertainties associated with the model completeness, until now, the PEA model is focusing on representative situations according to the various means and systems retained in the DHR strategy; the model is then partial and the PEA results should be affected by a large amount of uncertainties. The next PEA model, for which initiating events and scenarios coverage will be enlarged, may lead to a reduction of model uncertainties.

In addition to these common sources of uncertainties for probabilistic models, the GFR PEA model introduces technological risk uncertainties (i.e., ability to develop an innovative component or system, and uncertainties related to the ability of an innovative system to perform the mission it was designed for). Another significant feature of this probabilistic assessment representation of the 2400 MWth GFR will be the combination of systems and T-H reliability models.

\section{IDENTIFICATION AND QUANTIFICATION OF THE SOURCES OF UNCERTAINTIES FOR THE NATURAL CIRCULATION PERFORMANCE ASSESSMENT}

\subsection{Influence of the time limit before the loss of the forced circulation decay heat removal (FCDHR) process}

In order to define the most relevant case for the RMPS exercise, sensitivity studies were performed with the CATHARE
2 code. Due to its relatively high-occurrence frequency in the GFR PEA (i.e., $10^{-2} /$ reactor - year), the short duration loss of offsite power transient (LOOP $<2$ hours) is considered as reference scenario for the pressurized situation depiction. As stated here above, the forced circulation of primary helium is foreseen in the first stage to remove the core decay heat. In the LOOP situation, the electrical supply will be provided by emergency diesel generators (EDGs) or batteries (1 unit per electrical train) to the dedicated circulators. The combination of components losses leading to the complete loss of FCDHR at initiating event (e.g., EDGs fail to start or DHR circulators failures) provides the most stringent case in terms of decay power.

For the 2400 MWth GFR, neutronic calculations were performed with the Darwin code [11] to estimate the decay heat curve for several minor actinides contents. As reported in Figure 4, the core power decreases to around 15\% of nominal value just after the control rods full insertion, and decreases rapidly to $3 \%$ of nominal power five minutes after scram.

Despite the weak occurrence probability of such failures combination, it seems clear that this situation would provide the most stringent case for NCDHR performance and reliability assessment (maximum core power). On the other hand, just after the reactor scram, the pressure level in the primary circuit and the density difference between hot and cold parts of the DHR loop are maximum, providing potential high-engaged forces for natural circulation. Sensitivity 


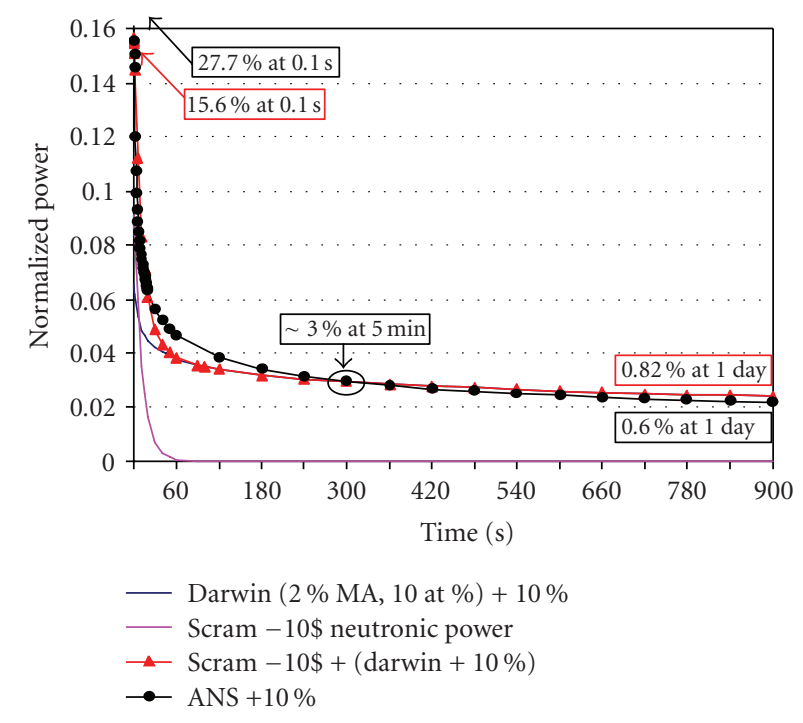

FIgURE 4: GFR 2400 MWth core decay heat evolution with time.

studies were performed with the CATHARE 2 code to assess the influence of the T-H system parameters (core decay heat included) at NCDHR actuation, for example, after the FCDHR phase. Several times before NC, actuation was investigated in comparison with the a priori most severe case (NCDHR actuation at initiating event, representative of a blackout transient).

In Figure 5 are reported the primary pressure evolutions with time for time limits before FC loss ranging from 1 to 24 hours. As a result, one should notice that the primary circuit pressure evolutions are similar, monotonic, and ranging from 7.0 to $5.4 \mathrm{MPa}$ during the first 24 hours.

Correlatively with the primary pressure evolutions, the mass flow at core inlet ranges from 23 to $30 \mathrm{~kg} / \mathrm{s}$ in an FC operating mode (due to a DHR blower rotational speed control scheme, so that DHR circuit pressure drop and blower pressure rise would be matched for an unchanged mass flow rate when pressure decreases) and from 32 to $25 \mathrm{~kg} / \mathrm{s}$ in natural circulation (see Figure 6). Indeed, according to the circulator performance map depiction in the CATHARE 2 model, the mass flow at DHR loop outlet is inversely proportional to the primary pressure level when the circulator(s) is in operation. When they fail, the natural circulation is established at a mass directly depending on the pressure level in the circuit.

In Figure 7 are reported the maximum temperature evolutions in the core with time. In line with the mass flow at core inlet (between 32 and $20 \mathrm{~kg} / \mathrm{s}$ ), and the decay heat to extract (between 3 and 0,6\%, resp., 5 minutes and 24 hours after scram), the maximum temperature in the core is monotonically decreasing. As a result, one should notice that results do not depend on the time limit before FCDHR loss, indicating that the heat extraction potential by the secondary and ternary DHR circuits is largely enough to cope with these situations.

In summary, the core decay heat and primary pressure levels at NCDHR actuation do not appear as critical parameters for the reliability and performance assessment of this

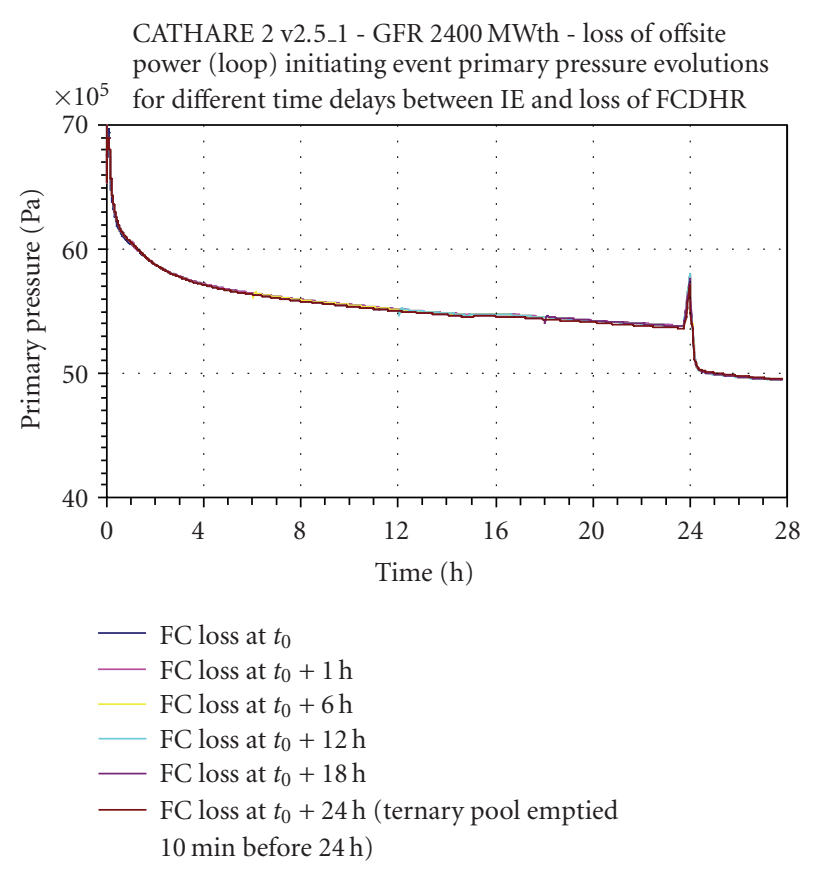

FIgURE 5: Influence of the time limit before NC actuation on the primary pressure evolutions (1 DHR loop available).

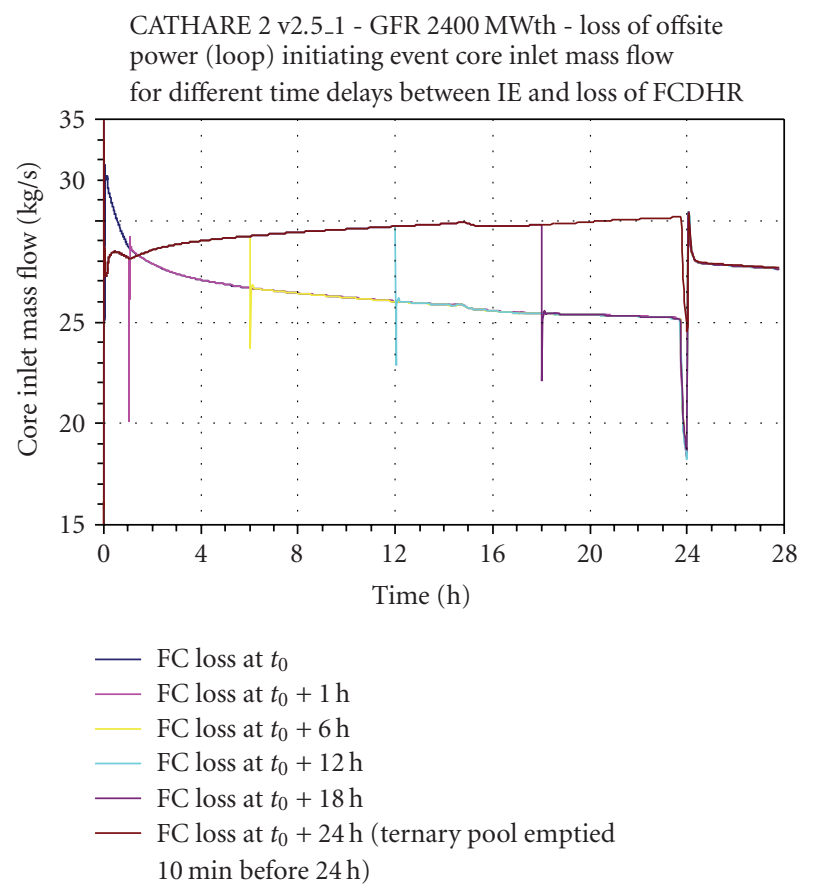

FIGURE 6: Influence of the time limit before NC actuation on the core inlet mass flow evolutions (1 DHR loop available).

passive system. Moreover, as the time delay before FC failure is not influencing the NCDHR performance, it validates the event representation in a Boolean model for the GFR PEA, as all active system failures during the first 24 hours are aggregated as they occur at initiating event ("static" probabilistic model). 


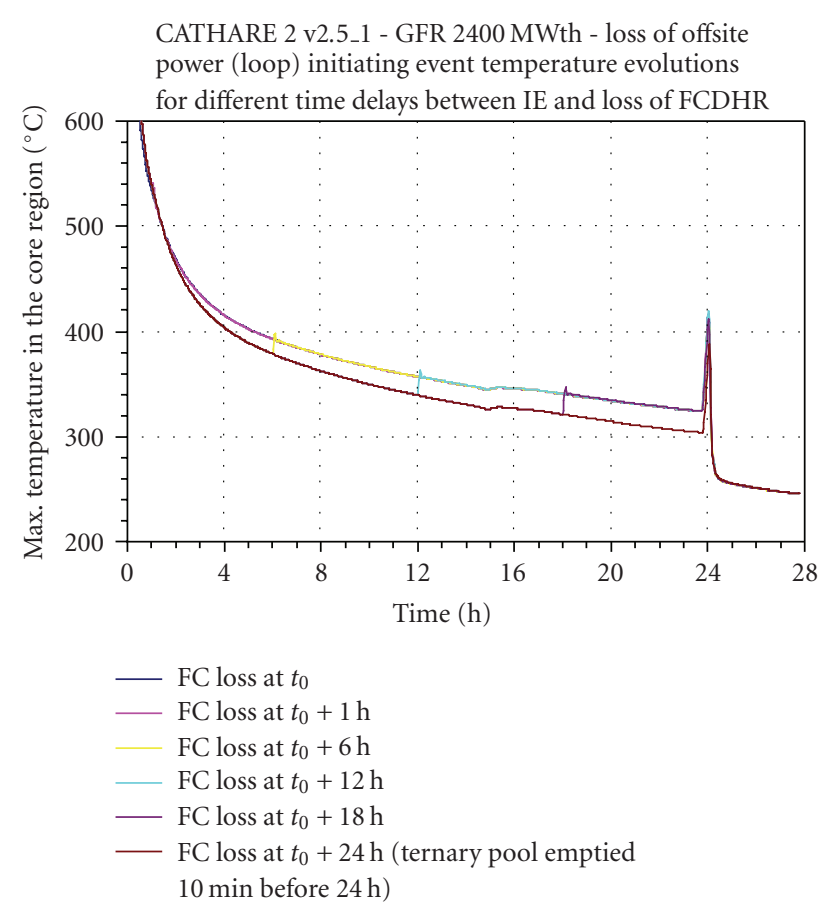

FIGURE 7: Influence of the time delay before NC actuation on the core temperatures evolutions (1 DHR loop available).

\subsection{Other elements related to the NCDHR question}

Owing to the DHR system features design, it is worth noticing that primary gaseous coolant NC performance is directly related to the natural circulation capability in the secondary side pressurized water circuit (around 1.0 MPa) through the heat exchange coefficient in the DHX. Then, the frame of RMPS exercise for the GFR DHR system is involving a "twoin-one" exercise: one for gaseous coolant, the second for pressurized water natural circulation.

Regarding the NC loop in the primary circuit (from the core to the dedicated heat exchanger for DHR), the natural circulation of a gaseous coolant may be subject to several and diverse "disruptions" potentially challenging its capability to achieve the function it was designed for. One important feature of gas is owing to the fact that viscosity is increasing with temperature. Then, since the viscosity increases as the temperature of the gas increase, the Reynolds number decreases. For the DHR operating conditions, the flow regime is laminar and friction losses are proportional to the inverse the Reynolds number (eventually with an exponent, named $m$, i.e., $\left.f \propto \mathrm{Re}^{-m}\right)$. Thus as the temperature increases along the channel, friction losses rise leading potentially to the flow blockage. For a single gaseous heated channel (i.e., one single core channel), the laminar flow instability may lead to flow blockage that could be expressed in terms of temperature difference between the inlet and the outlet of this channel. These results may be obtained with a simplified development of the momentum equation in a steady-state approach.

For the GFR core, assuming two enrichments core zones and a radial power profile of about 1.2 (i.e., "parallel" heated channel characterized by different generated power levels), flow redistribution due to viscosity effects in the hottest core channels (increased pressure drop compared to other parallel channels) could occur. Within this frame, simplified methods could not be employed and the use of the CATHARE 2 code is required.

Regarding the DHR secondary circuit, the natural circulation phenomena are driven by the density (i.e., typically temperature for pressurized water) change between hot (i.e., secondary side of the primary to secondary HX) and cold (i.e., primary side of the secondary to pool HX) parts of the loop, then by the exchange at the interfaces between circuits.

\subsection{Identification of critical parameters}

\subsubsection{Mission of the system}

As reported in Section 2, the major mission of the DHR system is to remove the core decay heat during the mission time defined for the two representative scenarios:

(i) from nearly 0 to 24 hours for pressurized situations (with intact helium pressure boundary);

(ii) from 24 to 168 hours for depressurized ones (this mission time is related to the choice made for the simplified PSA application for GFR); in a first approach, the mission success will be checked at 48,72 , and 168 hours after the initiating event, assuming the electrical supplies recovery at these successive time delays.

For both situations, it is implicitly assumed that additional measures will be taken in order to guarantee a safe termination of the transient (mobile active systems linked to the guard containment, for example, recovery of electrical supplies allowing for a forced circulation transient termination).

\subsubsection{Failure criteria}

The DHR system failure criteria are defined as the failure to maintain a decay heat removal rate that is required to limit vital component temperatures (vessel boundary, core plates) to the values of the "IVth category" design safety limits defined, to date, for GFR safety studies:

(i) $1600^{\circ} \mathrm{C}$ for fissile core (cladding temperature),

(ii) $1250^{\circ} \mathrm{C}$ for $\mathrm{He}$ temperature in upper plenum (vessel structures).

By now, these failure criteria are based on preliminary values used for GFR design and safety studies. In parallel, some $\mathrm{R} \& \mathrm{D}$ effort is provided by CEA in order to increase our confidence for future studies.

At this point, it is worth to notice the close interaction between deterministic and probabilistic studies in support to the safety demonstration. Uncertainties taken into account through the RMPS exercise will furnish and quantify safety margins reservations for the deterministic analysis.

\subsubsection{Failure modes and critical parameters identification}

It seems not always obvious to associate a failure mode to the mission of the system due to the complexity of T-H 


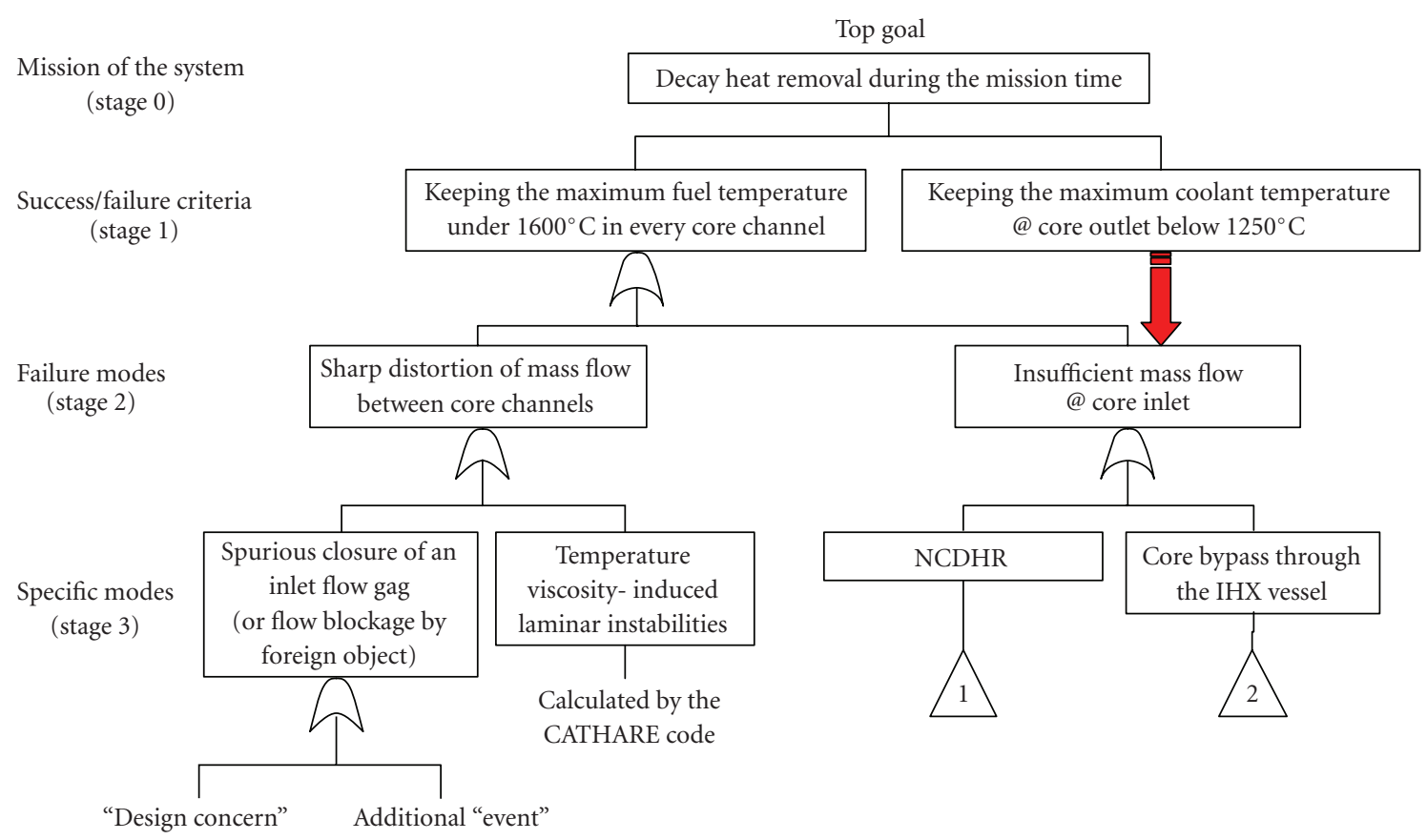

FIGURE 8: Deductive approach for RMPS critical parameters determination.

phenomena and interaction between the passive system and components present in the fluid potential pathway. As proposed in [5], a qualitative analysis as the failure mode and effect analysis (FMEA) could be performed (with a "virtual component" for NC process simulation) to help defining critical parameters.

The proposal is to determine the critical parameters according to "engineering judgment" based upon a simplified "deductive analysis" (or cause consequence analysis). This approach is chosen due to the complexity of the involved phenomena reported here above, an FMEA starting from components failure mode and ending at consequences, as the "deductive analysis" is more attached to physical phenomena. Furthermore, the method employed for the critical parameters determination is linked to the level of detail of the systems. As yet, the GFR concept is still under development and, therefore, the design is not strictly fixed.

The cause-consequence diagrams for this deductive analysis are developed upon simplified principles:

(i) $\mathrm{T}-\mathrm{H}$ parameters like pressure, temperature, and gas densities and velocities are calculated by the CATHARE 2 code; therefore, they are not appearing in block diagrams introduced in the development of trees;

(ii) according to the former point, the analysis is then based on the development of diagrams in a "quasi" steady-state approach (a time- and space-dependent analysis being to complicate without the use of a detailed T-H code); at each stage, the cause potentially leading to the consequence placed above is developed until "critical parameters" like code user parameters (e.g., valves opening fraction, i.e., related singular pressure drop) or specific T-H features characterized by a lack of knowledge (e.g., $\mathrm{N}_{2}$ fraction reentering in the primary circuit through the break) are reached;

(iii) in most cases, the analysis is developed in consistency with the foreseen flow circulation, for example, starting from the core region going into a dedicated DHR loop, passing through the DHX, the stopped blower (or the ejector in an alternative design) and the isolation valve (potentially not fully closed) exiting above the downcomer and reentering in the core.

The first step for the determination of critical parameters based on this deductive analysis is represented in Figure 8. Starting from the defined mission of the system (decay heat removal during the mission time), referenced as Stage 0, the success/failure criteria (see Section 4.3.2) are developed just under this "top goal" (Stage 1). For the first success/failure criteria (keeping the maximum fuel temperature under $1600^{\circ} \mathrm{C}$ in every core channels), two potential failure modes during the transient phase are defined. Concerning the second success/failure criteria (keeping the maximum coolant temperature at core outlet below $1250^{\circ} \mathrm{C}$ ), we implicitly assume that the gas flow (and temperature) harmonization at core channels outlet is sufficient to consider the reduction of mass flow at core inlet as the only mean for leading to unacceptable temperature for upper head internal structures (assumption schematized by a red arrow in Figure 8). In complement to the former point, it is worth to notice the following:

(i) first, the gas temperature at each representative channel output could be a meaningful indicator for this success/failure criteria, if needed;

(ii) secondly, the precise calculation of heat exchange between the coolant and the upper head structures 


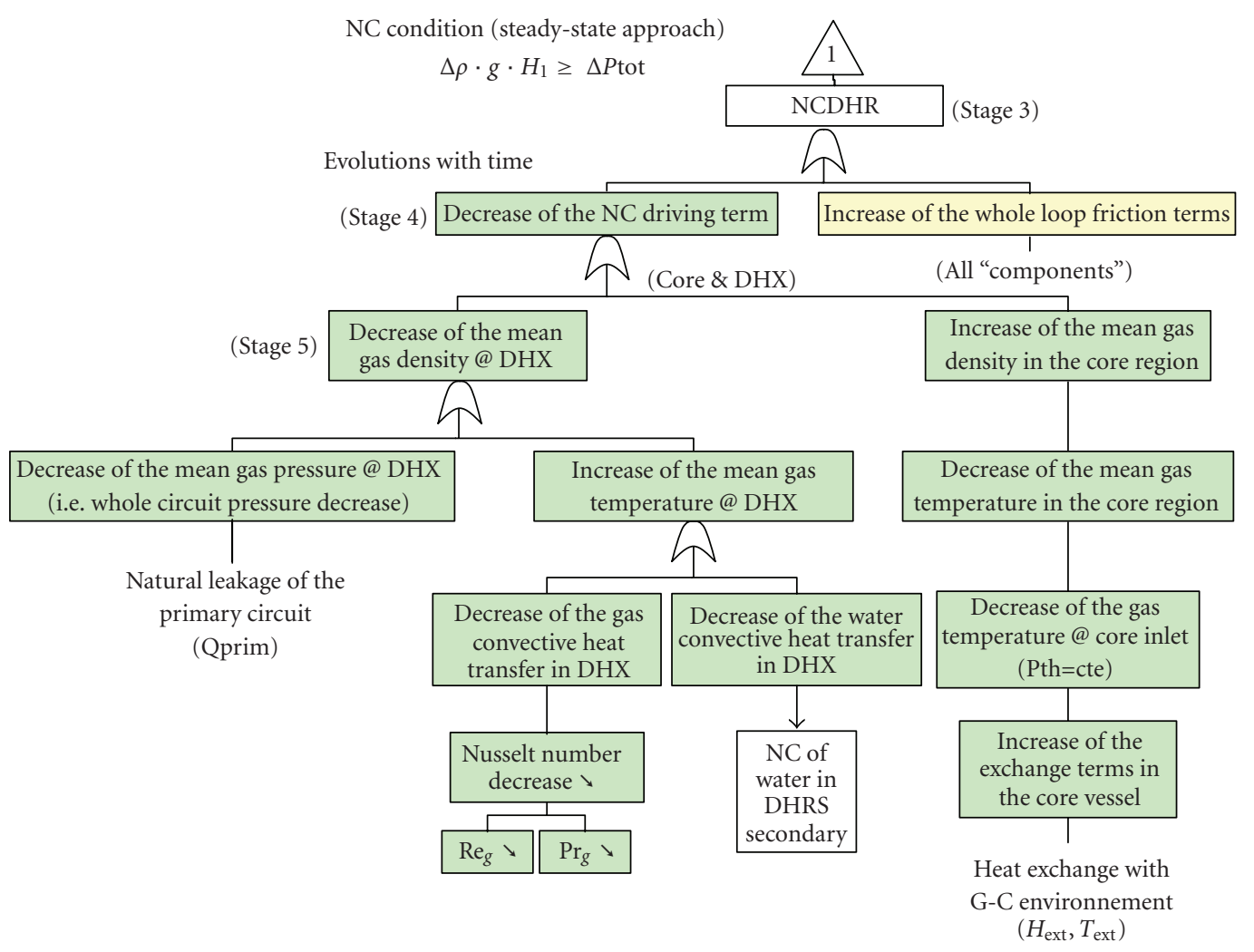

FIGURE 9: Development of the deductive approach for critical parameters determination (NCDHR pressure drops “1”).

necessitate a multidimensional code due to the probable internal circulation of gas in the upper plenum.

The next step is then to develop the success/failure criteria into the potential failure modes (Stage 2). Two ways were determined leading to the increase of the maximum fuel temperature in a core channel, which are as follows:

(i) the apparition of a "sharp distortion of mass flow between core channels;"

(ii) an "insufficient mass flow at core inlet."

At this point, it seems important to remark that the first failure mode addresses exclusively to the core region, as the second is more related to the gas flow path from the core boundaries (through the DHR system and eventually through the main loops if they are not fully closed).

The distortion of mass flow between different core channels could be associated with the following:

(i) a "spurious closure of an inlet flow gag or flow blockage by foreign object:" it is assumed that inlet flow restrictions located at assemblies entrance are designed for a gas outlet temperature equalization at nominal full power (avoiding hot spots for upper head internal structures and providing an optimized fuel consumption during the batch cycle); the "inadvertent" closure would then be assimilated as an "additional event" following the initiating event. This point is also applicable to the potential flow blockage by a foreign object (or eventually by accumulation of foreign materials) at core inlet;

(ii) the "temperature viscosity-induced laminar instabilities" phenomena for single heated and, by consequence, for parallel core channels.

Concerning the insufficient mass flow at core inlet, this consequence is associated with the following:

(i) a DHR system-related cause (linked to the "NCDHR" capability);

(ii) a main circuit-related cause ("core bypass through the IHX vessel”).

The development of the cause-consequence diagram for the first point is depicted in Figure 9 (Stage 3). The steady-state approach is employed in order to assess the critical parameters for the NC phenomenon with the dedicated decay heat exchanger. The mass flow decrease at core inlet is linked either to a "decrease of the NC driving term" or to an "increase of the whole loop friction terms" (starting from the core inlet, passing through the DHR specific components, flowing in core vessel, and down to the core), referenced as Stage 4 .

The "driving term" is decomposed into the gas densities difference and the driving height for NCDHR. It is assumed that thermal dilation of materials (i.e., variation of the driving height) is negligible compared to the potential variation of gas densities difference. Therefore, the "driving term decrease" is only related to the gas densities difference variation, which decomposes in a "decrease of the mean gas density at 


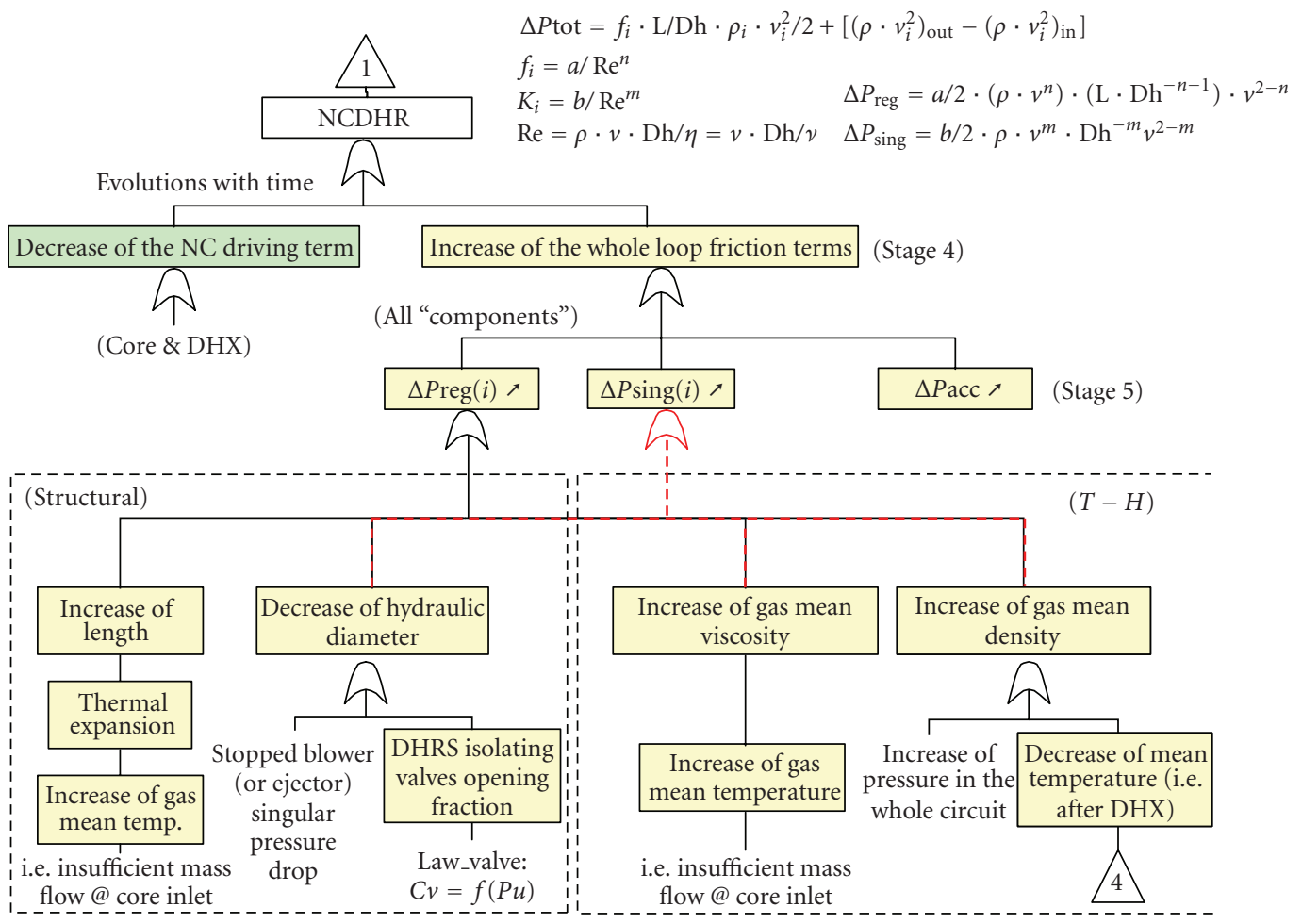

FIGURE 10: Development of the deductive approach for critical parameters determination (NCDHR pressure drops “2”).

DHX" and/or an "increase of the gas density in the core region" (Stage 5). This increase is related to the critical parameter ECPLAQ, which corresponds to a multiplicative factor for core materials to fluid heat transfer coefficient.

At DHX primary side, the perfect gas law is employed for defining the causes of a mean gas density decrease, for example, a "decrease of the mean gas pressure at DHX" and/or an "increase of the mean gas temperature at DHX." Concerning the pressure decrease, we talk about a pressure decrease not due to a pressure drop increase until the DHX is reached (this effect being reviewed during the development of the "increase of the whole loop friction terms" block), but consecutive to a whole circuit pressure decrease. This pressure dropoff in the primary circuit is assumed to be driven by the "primary circuit natural leakage" (critical parameter, named FUITE). For the gas mean temperature at DHX primary side, its increase is attributed to the "decrease of the gas convective heat transfer in DHX" and/or to the "decrease of the water convective heat transfer in DHX" (parameter, named ECDHX1 hereafter).

Concerning the gaseous side, the convective heat transfer is proportional to the gas mean heat conductivity, to the hydraulic diameter in the DHX primary side, and to the inverse of the Nusselt number of the flow. As for the driving height variation with temperature (thermal dilatation), the hydraulic diameter decrease is not taken into account for the determination of critical parameters. This means that the material accumulation (i.e., fouling) of the DHX at primary side is not judged as critical as variations of the gas T-H prop- erties (driving term concern), or as singular pressure drop along the flow path (stopped blower, isolating valve).

The development of the block entitled "decrease of the water convective heat transfer in the DHX" emphasizes the so-called "two-in-one" RMPS exercise. Indeed, as the DHR system secondary side is made of pressurized water $(1.0 \mathrm{MPa})$ set in motion by natural circulation with an above-positioned immerged heat exchanger (with a dedicated pool), one should extend the RMPS exercise frame to the DHR secondary side. According to previous work performed for potential passive systems designed for pressurized water reactors, the critical parameters for this part of the RMPS application are directly issued from [5]. Then, in the DHR secondary side, the characteristic parameters will be as follows:

(i) the initial temperature of water in the pool (named T2DHR);

(ii) the mean temperature of pressurized water in DHR system (i.e., the pool temperature T2DHR due to secondary-to-ternary thermal equilibrium);

(iii) the pressure in DHR system secondary side (named P2DHR);

(iv) the rate of incondensable gases at the inlet of the pool HX (simulating a potential leakage through the DHX);

(v) the fouling of the pool HX;

(vi) the number of broken tubes in the pool HX. 
The last three critical parameters are jointly described by a corrective factor of the exchange coefficient between secondary and ternary "circuits", that is, ECDHX2.

The decrease of NC driving term (Stage 4) could also be a result of a spurious "increase of the mean gas density in the core region." Assuming the gas gaseous coolant as a perfect gas, this density increase is attributed to a pressure increase and/or to a mean temperature decrease. Assuming that the pressure increase will solely be caused by a lack of heat extraction (i.e., a DHR loop inadvertent closure, or a lack of extraction by secondary circuit, which is the main issue of the RMPS exercise), the gas mixture increase in the core region is only attributed to the mean gas temperature decrease. The mean temperature decrease is, therefore, consecutive to a gas temperature decrease at core inlet and then to increased exchange terms in the core vessel (not considered for this first analysis) or at DHX (critical parameter ECDHX1).

As for the determination of the critical parameters related to the "driving term" concern, the same approach is followed for the "increase of the whole loop friction terms." The analysis focuses on the regular and singular pressure drop on the flow path of the gaseous mixture (in the representative "loop" starting from the core inlet). In Figure 10 is depicted the development of the block diagram for the potential increase of "whole loop" pressure drops. In dashed lines are represented two groups characterized by "structural" (singular pressure drops) and "T-H” (regular pressure drops) concerns.

It is worth to notice that only four "major components" are taken into account at the flow path for pressure drop analysis: the core assemblies (including for each representative one the inlet flow gag, the lower and upper neutron shielding zone, and the fissile part), the DHX, the DHR blower (singular pressure drop when stopped), and the isolation valve. This choice is performed according to the meaning that they will be the most important contributors for the whole "loop" pressure drops. Moreover, this choice is linked to the present complexity of the CATHARE 2 model for the GFR concept whose design is still in progress.

According to this development, and to the sources of known uncertainties in the CATHARE 2 model, critical parameters potentially challenging the engaged forces are related to the plate-type core regular pressure drop in laminar conditions (FRPLAQ), the turbulent-to-laminar transition Reynolds number (REPLAQ) for exchange (cf., ECPLAQ above) and regular pressure drop assessment in the core region, and the singular pressure drop provided by the stopped DHR blower (DPSOUF). In a first step, the singular and regular pressure drop at DHR heat exchanger are not taken into account, owing to the fact that correlations for circular tubes are less subject to large uncertainties. In anyway, a sensitivity study is reported at the end of this document and related to the impact of pressure drop reservations on margins to failure/success criteria. This work is performed through the DHR loop isolating valves partial opening and is finally translated into additional pressure drops in the loops. Therefore, they should also be investigated as a combination of other singular pressure drops in the loop (for DHR HX, e.g.).

\section{RELIABILITY EVALUATION OF PASSIVE SYSTEMS WITH THE CATHARE 2 CODE}

\subsection{The CATHARE 2 model for GFR}

The complete CATHARE $2[12,13]$ model for $2400 \mathrm{MWth}$ GFR is composed of the following:

(i) the primary circuit with helium as coolant, includingthe main reactor vessel comprising the core, three principal-independent loops each containing a finned plate intermediate heat exchanger (IHX) and a blower, three tanks for helium supply (for guard containment pressure), and three dedicated DHR loops, each with its own water-filled secondary and pool-type ternary circuits;

(ii) each principal loop has its own secondary circuit for power conversion, includingthe second part of IHX, a single shaft-mounted turbomachinery, and a steam generator; the working fluid in the secondary circuit is a mixture of helium and nitrogen with mass fractions, respectively, equal to $20 \%$ and $80 \%$;

(iii) a ternary steam-water circuit (second part of the oncethrough counter-current plate-shape steam generator).

Each dedicated DHR loop is composed of the following:

(i) a primary loop (crossduct connected to the core vessel), with a driving height of $10 \mathrm{~m}$ between core and DHX midplan;

(ii) a secondary circuit filled with pressurized water at 1.0 $\mathrm{MPa}$ (driving height for NCDHR of $5 \mathrm{~m}$ );

(iii) a ternary pool, initially at $50^{\circ} \mathrm{C}$, whose volume is determined to handle one-day heat extraction (after this time delay, additional measures are foreseen to fill up the pool).

In addition, a large free volume filled with nitrogen is described for guard containment simulation in case of a depressurization accident. This free volume is hydraulically and energetically linked to the primary circuit by specific functionalities implemented in the CATHARE 2.5 version.

A special care was put on the core model, taking into account the heterogeneous plate structure, the core radial dimension and power profiles (6 hydraulics channels with singular pressure drop in order to equalize the outlet temperature in nominal conditions, etc.).

In Figure 11 are reported the main features of one dedicated DHR loop modeled in the CATHARE 2 input data deck for 2400 MWth GFR [14].

\subsection{Critical parameters distributions and sampling}

The first class of parameters addresses the specific uncertainties associated with factors on which the magnitude of the engaged forces and counter forces depends (values of heat transfer coefficients and pressure losses) on the following:

(i) in the core region: correlations used to calculate the Nusselt number and the friction factor have different functional forms depending on the geometry, fluid 


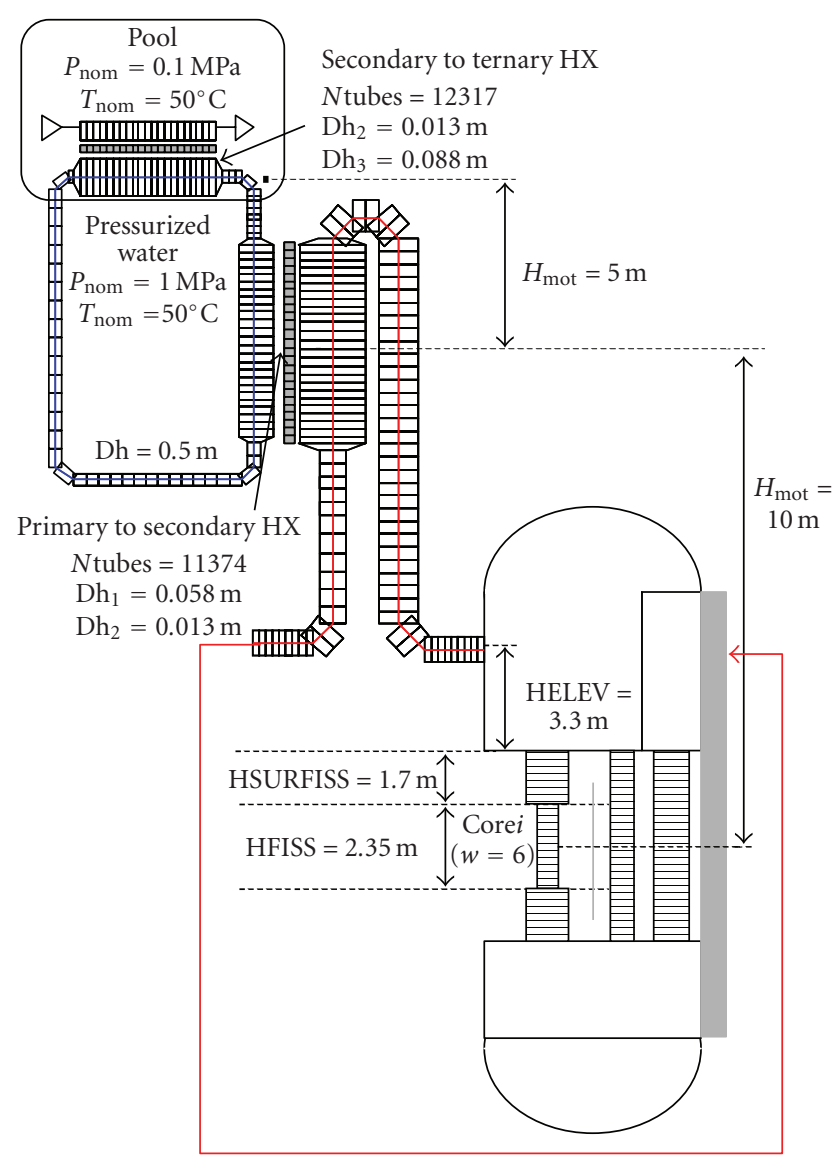

FIGURE 11: DHR loop features and nodalization in the CATHARE 2 code.

characteristics, and flow regime (forced, natural, or mixed); as natural and mixed convection correlations are not supported by extensive experimental results, the resulting correlations in natural convection laminar regime are subject to large uncertainties; for the GFR core (plate-type core), an R\&D program is underway in CEA to establish specific correlations for these geometry and T-H conditions [15]; however, multiplicative factors are retained in the present CATHARE 2 input data deck for exchanging coefficients and regular friction factors in laminar regime (the transition regime Reynolds number being also a critical parameter);

(ii) in the DHR loop: exchange coefficients multiplicative factors for primary to secondary, and from secondary to ternary pool heat exchangers.

The second class of parameters addresses the uncertainties associated with the potential discrepancy of $\mathrm{T}-\mathrm{H}$ parameters at transient initiation:

(i) a first subclass is related to the ternary and secondary DHR circuits initial temperature and pressure; by this way, we implicitly assume that small deviations are possible within the allowable range defined by the protection system; therefore, these parameters are charac-
TABLE 1: Critical parameters distributions.

\begin{tabular}{lcccc}
\hline & Mean & Distribution & Min. value & Max. value \\
\hline T2DHR & $50^{\circ} \mathrm{C}$ & Normal & $42.5^{\circ} \mathrm{C}$ & $57.5^{\circ} \mathrm{C}$ \\
P2DHR & $1.0 \mathrm{MPa}$ & Normal & $0.85 \mathrm{MPa}$ & $1.15 \mathrm{MPa}$ \\
FRPLAQ & $15 \%$ & Normal & 0 & $30 \%$ \\
ECPLAQ & $5 \%$ & Normal & 0 & $10 \%$ \\
REPLAQ & 5000 & Normal & 4000 & 6000 \\
ECDHX1 & $5 \%$ & Normal & 0 & $10 \%$ \\
ECDHX2 & $5 \%$ & Normal & 0 & $10 \%$ \\
DPSOUF & $15 \%$ & Normal & 0 & $30 \%$ \\
\hline & Max. & Distribution & Lower bound & Upper bound \\
\hline FUITE & $2 \mathrm{e}-04$ & Triangular & $2 \mathrm{e}-5$ & $2 \mathrm{e}-3$ \\
\hline
\end{tabular}

TABle 2: Mean, standard deviation (SD), and upper and lower bounds for critical parameters after LHS (100 values).

\begin{tabular}{lcccc}
\hline & Mean & SD & Min. value & Max. value \\
\hline T2DHR & 50.009 & $3.308 \mathrm{e}+00$ & $4.293 \mathrm{e}+01$ & $5.720 \mathrm{e}+01$ \\
P2DHR & $9.998 \mathrm{e}+05$ & $6.625 \mathrm{e}+04$ & $8.583 \mathrm{e}+05$ & $1.144 \mathrm{e}+06$ \\
FUITE & $7.40 \mathrm{e}-04$ & $4.487 \mathrm{e}-04$ & $6.287 \mathrm{e}-05$ & $1.812 \mathrm{e}-03$ \\
FRPLAQ & $1.50 \mathrm{e}-01$ & $6.639 \mathrm{e}-02$ & $5.444 \mathrm{e}-03$ & $2.972 \mathrm{e}-01$ \\
ECPLAQ & $4.99 \mathrm{e}-02$ & $2.212 \mathrm{e}-02$ & $4.632 \mathrm{e}-05$ & $9.773 \mathrm{e}-02$ \\
REPLAQ & $4.99 \mathrm{e}+03$ & $4.411 \mathrm{e}+02$ & $4.063 \mathrm{e}+03$ & $5.930 \mathrm{e}+03$ \\
ECDHX1 & $4.99 \mathrm{e}-02$ & $2.211 \mathrm{e}-02$ & $1.423 \mathrm{e}-03$ & $9.634 \mathrm{e}-02$ \\
ECDHX2 & $4.99 \mathrm{e}-02$ & $2.213 \mathrm{e}-02$ & $2.564 \mathrm{e}-03$ & $9.888 \mathrm{e}-02$ \\
DPSOUF & $1.50 \mathrm{e}-01$ & $6.614 \mathrm{e}-02$ & $6.816 \mathrm{e}-03$ & $2.895 \mathrm{e}-01$ \\
\hline
\end{tabular}

terized by lower and upper bounds between $-15 \%$ and $+15 \%$ around their nominal values;

(ii) the second subclass concerns the primary circuit natural leakage (named FUITE), and is very concept dependant (number of loops, nozzles, sealing systems for rotating machines, etc.).

The critical parameters and their distribution features are given in Table 1, which have been established by engineering judgment.

Owing to the precision required for this first NCDHR performance and reliability assessment, and compared to the magnitude of other sources of uncertainties in the PEA model, the number of calculations is first limited at 100 . An optimized Latin hypercube sampling (LHS) is then performed according to the distributions and bounds selected reported in Table 1 and furnishes a set of values as input parameters for the CATHARE 2 calculations. In Table 2 are given the mean, standard deviation, and minimum and maximum values for each critical parameter after LHS.

In Figures 12, 13 are, respectively, plotted the 100 values and the final distribution for the first critical parameter, for example, T2DHR, in order to check the consistency of the sampling.

\subsection{RMPS exercise results}

The process followed for this RMPS exercise implies to combine the steady state (due to the secondary circuit pressure 


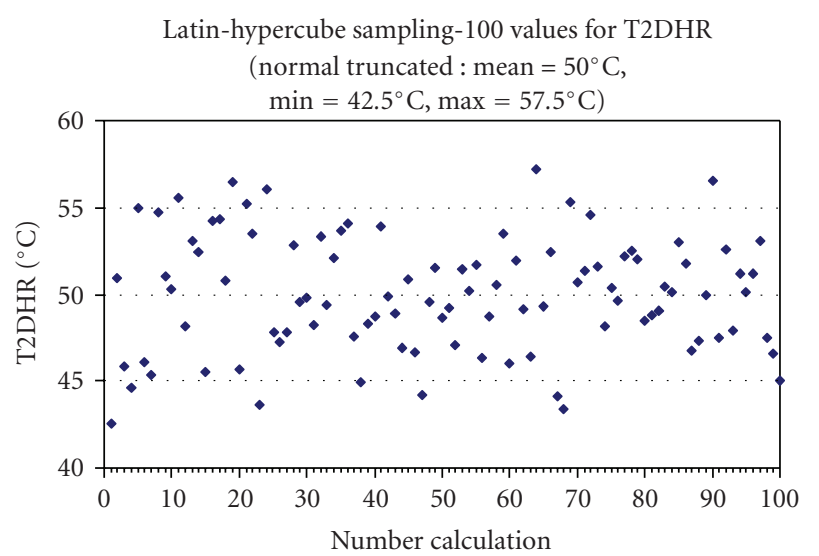

FIGURE 12: Optimized LHS (100 values for T2DHR).

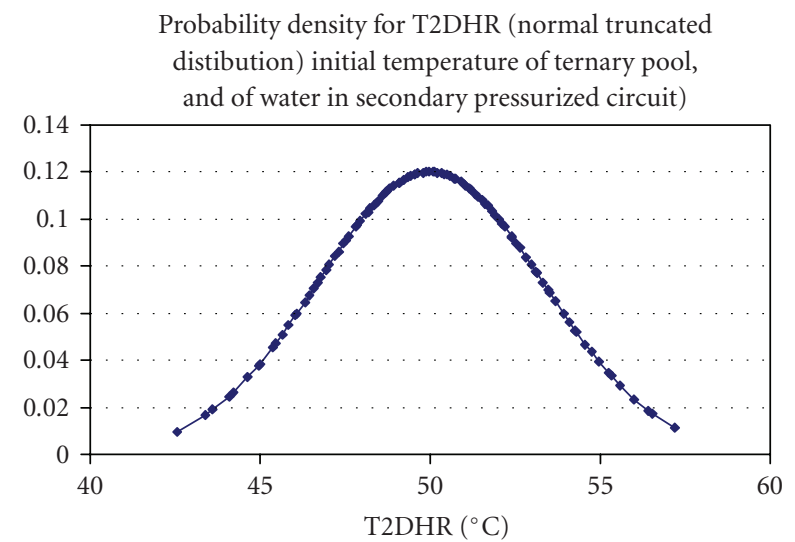

Figure 13: Verification of the T2DHR distribution after sampling.

and ternary pool temperature initialization) and the transient calculations with CATHARE 2. Each calculation takes around 5000 seconds CPU on a personal computer under LINUX operating system.

The results obtained with the CATHARE 2 code are plotted in Figure 14 showing the core maximum temperature evolution with time.

As shown by Figure 14, a sharp decrease of the core temperature occurs during the first minute of the transient due to the reactor scram and the main blower rundown on their inertia. Until the NCDHR is established, the temperatures are increasing up to around $1030^{\circ} \mathrm{C}$ and then decrease owing to the large amount of energy exchanged with the secondary (and ternary) DHR circuit. As a result, one should notice the weak discrepancy of the temperature evolutions with time and of the maximum level reached. In Figure 15 is reported the maximum temperature distribution for these $100 \mathrm{calcu}-$ lations. At this stage, it is worth mentioning the robustness of the CATHARE 2 code as around 94\% calculations performed provide results (6 calculations exiting without results).

This temperature distribution is characterized by a mean value of $1029^{\circ} \mathrm{C}$ and a standard deviation of $4.3^{\circ} \mathrm{C}$ (see Table 3).

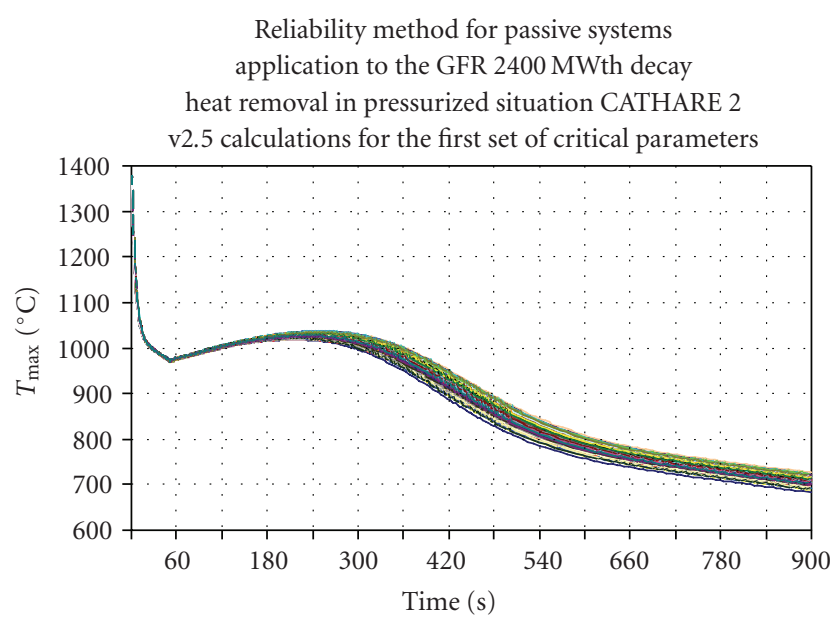

FIGURE 14: RMPS reference case-maximum temperature in the core region evolutions.

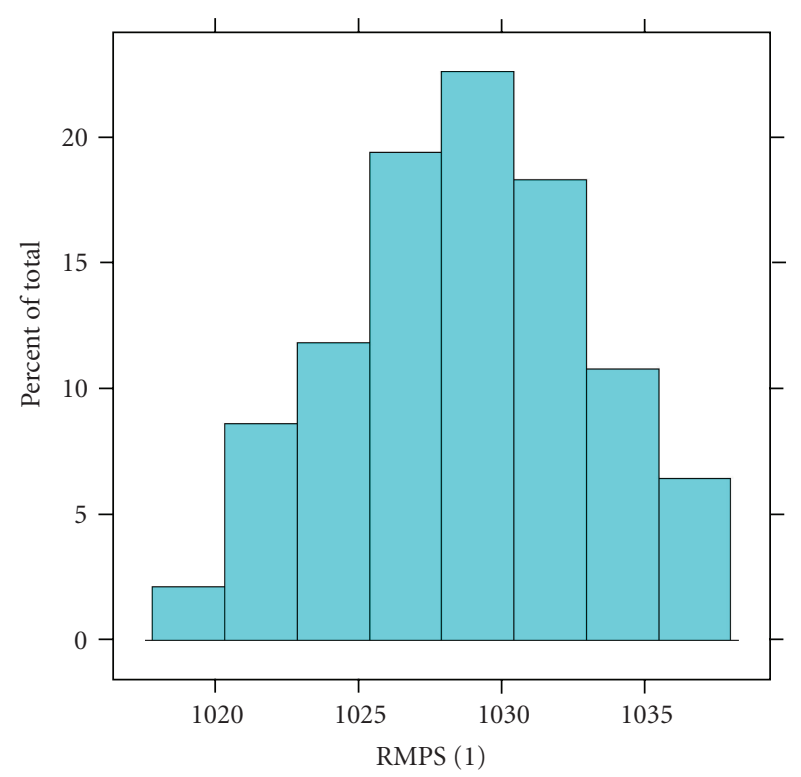

FIGURE 15: RMPS reference case-maximum temperature in the core region distribution.

TABLE 3: Results for the RMPS reference case.

\begin{tabular}{lcccc}
\hline & Mean & SD & Lower & Upper \\
\hline TMAX $\left({ }^{\circ} \mathrm{C}\right)$ & 1029 & 4.32 & 1019 & 1037 \\
TUPPER $\left({ }^{\circ} \mathrm{C}\right)$ & 907 & 2.35 & 903 & 913 \\
\hline
\end{tabular}

Compared to the failure/success criteria fixed at $1600^{\circ} \mathrm{C}$ as mentioned earlier in this document, the results obtained with the CATHARE 2 code are exhibiting the safety margin conferred by the DHR loop structural and thermodynamical design. For the ongoing PEA, it seems that the reliability of the natural circulation in pressurized situation is close to unity. In order to determine a more precise value of the NCDHR unreliability (if necessary, according to the magnitude of the other sources of uncertainties in the PEA model), 


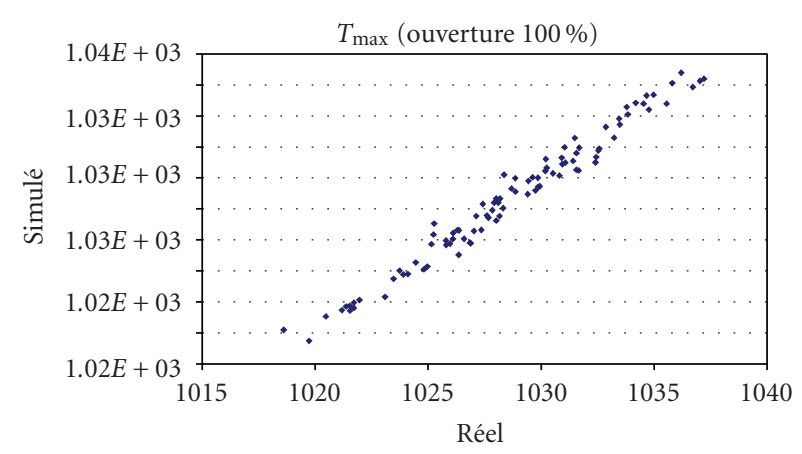

FIGURE 16: Real versus simulated maximum temperature in the core region.

the percentile corresponding to $1600^{\circ} \mathrm{C}$ can be calculated. Another way to evaluate the NCDHR unreliability consists in the research of linear correlation between the response result and the input parameters, in order to increase the number of calculations with a low CPU cost.

\subsubsection{Correlations between input parameters and temperature results}

A linear correlation between TMAX (maximum temperature in the core region) and input parameters has been determined:

$$
\begin{aligned}
\text { TMAX }= & 1016.5+(\text { T2DHR } * 0.30211)-(\text { FUITE } * 449.71) \\
& +(\text { FRPLAQ } * 63.027)-(\mathrm{ECPLAQ} * 18.222) \\
& -\left(\text { REPLAQ } * 2.4157 * 10^{-3}\right)+(\mathrm{ECDHX} 1 * 5.5575) .
\end{aligned}
$$

It should be mentioned that this linear correlation is based only on 6 input parameters (the last three ones having a negligible influence for the response). The $\mathrm{R}^{2}$ coefficient of determination for this linear model is equal to $97 \%$. Figure 16 compares TMAX calculated by the CATHARE 2 code and simulated by the linear model.

According to this result, the utilization of linear standard regression coefficients is justified in order to rank the most influent parameters (see Table 4).

The ranking is based on absolute values, as the sign is indicating the effect of variation of the input parameter for the response. For TMAX, the most influent parameters are, according to importance, FRPLAQ (multiplicative factor for laminar NC pressure drop in the core region), REPLAQ (Reynolds number for turbulent to laminar transition in the core region), and T2DHR (ternary pool and secondary circuit temperature level at DHR initiation).

According to the above-mentioned linear regression, $10^{6}$ simulations are performed to increase the number of calculations (compared to the 100 ones performed with CATHARE 2 ) and then to improve the probability value of the NC reliability assessment in the PEA model.

The results are leading to a value of NCDHR unreliability performance less than $5 \cdot 10^{-6}$ with a confidence level above $99 \%$. It is worth to notice that this unreliability value is surely
TABLE 4: Linear correlation standard regression coefficient.

\begin{tabular}{lrcrc}
\hline & \multicolumn{2}{c}{ TMAX } & \multicolumn{2}{c}{ TUPPER } \\
& SRC & Rank & SRC & Rank \\
\hline T2DHR & $\mathbf{0 . 2 3}$ & $\mathbf{3}$ & $\mathbf{0 . 3 0}$ & $\mathbf{2}$ \\
P2DHR & 0.02 & 7 & -0.08 & 7 \\
FUITE & -0.05 & 5 & 0.08 & 5 \\
FRPLAQ & $\mathbf{0 . 9 6}$ & $\mathbf{1}$ & 0.01 & 9 \\
ECPLAQ & -0.09 & 4 & $-\mathbf{0 . 0 8}$ & $\mathbf{3}$ \\
REPLAQ & $-\mathbf{0 . 2 4}$ & $\mathbf{2}$ & $\mathbf{0 . 8 0}$ & $\mathbf{1}$ \\
ECDHX1 & 0.03 & 6 & -0.01 & 8 \\
ECDHX2 & 0.01 & 8 & -0.08 & 4 \\
DPSOUF & -0.01 & 9 & 0.08 & 6 \\
\hline
\end{tabular}

overestimated as the upper value of TMAX $\left(1041^{\circ} \mathrm{C}\right)$ estimated by $10^{6}$ simulations is far from the $1600^{\circ} \mathrm{C}$ limit. This result will be incorporated in the next PEA model.

\subsubsection{Sensitivity study upon the DHR isolating valve opening fraction}

Concerning the isolation valves opening fraction, the CATHARE 2 code requires an evolution law of the valve flow coefficient $(\mathrm{Cv})$ with the valve's stem position $(\mathrm{Pu})$. The assumption made in the input data deck is considering a linear evolution of $\mathrm{Cv}$ with $\mathrm{Pu}$ ranging from $10^{5}$ (for $\mathrm{Pu}=0$ ) and 0 $($ for $\mathrm{pu}=1$ ). The law valve expression in CATHARE 2 code is

$$
\mathrm{Cv}=\frac{3600 \cdot q}{27,3 \cdot Y \cdot \sqrt{x \cdot P_{a} \cdot \rho_{a} \cdot 10^{-5}}}
$$

where $Y=1-x /\left(3 \cdot F_{\gamma} \cdot x_{t}\right), x=\Delta P / P_{a}, F_{\gamma}=\gamma / 1.4 \approx 1,67 /$ $1.4, x_{t}=0.6804, q$ is the mass flow in sonic condition (in $\mathrm{kg} / \mathrm{s}$ ), $P_{\mathrm{a}}$ is the upstream pressure (in $\mathrm{Pa}$ ), $\Delta P$ is the pressure drop (in $\mathrm{Pa}$ ), $\rho_{\mathrm{a}}$ is the upstream gas density $\left(\mathrm{in} \mathrm{kg} / \mathrm{m}^{3}\right.$ ).

According to this expression and the bounding values of $\mathrm{Cv}$, it seems more efficient to translate the stem position in terms of additional singular pressure drop in the NC loop (and here provided by the DHR isolating valve). As reported in Figure 17, the pressure drop stays under $1000 \mathrm{~Pa}$ for a valve opening fraction above $25 \%$, and increases rapidly for a stem position less than $10 \%$ (around $10000 \mathrm{~Pa}$ for a stem position close to $7 \%$ ).

Sensitivity calculations were performed with the CATHARE 2 code in order to feel the impact of this additional pressure loss related to the valve depiction in the code (see Figure 18).

If we consider a maximum opened fraction for the DHR isolating valve of $10 \%$, the maximum temperature in the core is around $1400^{\circ} \mathrm{C}$. However, for this opened fraction (or additional pressure drop in the primary NC loop, evaluated at $5200 \mathrm{~Pa}$ according to the Cv versus Pu valve law), the gas temperature at core outlet reaches $1286^{\circ} \mathrm{C}$, that is, just above the $1250^{\circ} \mathrm{C}$ criteria defined in Section 4.3.2. For a valve opening fraction close to $7 \%$, which is giving an additional pressure drop in the $\mathrm{NC}$ loop of about $10000 \mathrm{~Pa}$, the $1600^{\circ} \mathrm{C}$ criterion is approximately reached. In Figure 19 are reported the maximum temperatures in the core region and of the gas at core 


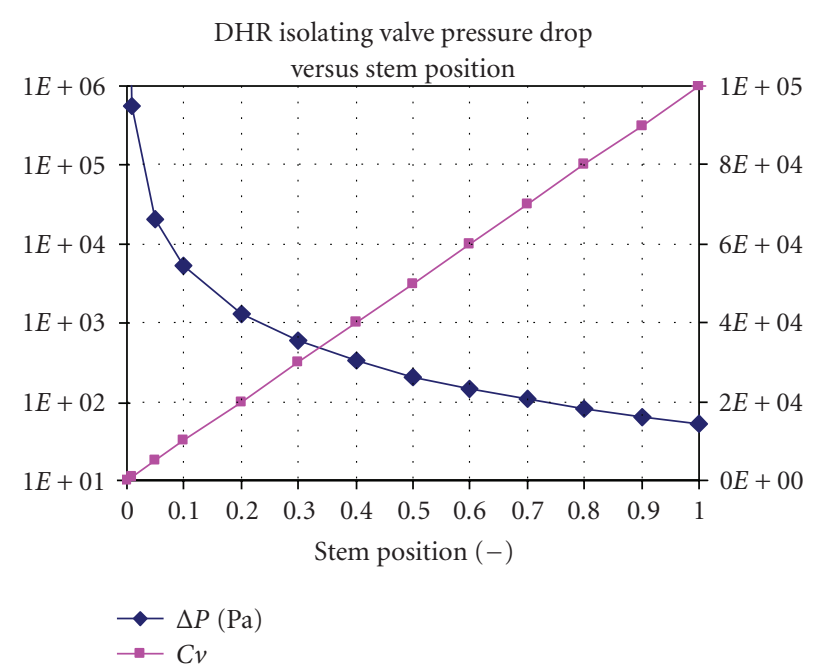

FIgURE 17: Flow coefficient and related pressure drop versus stem position for DHR isolating valves.

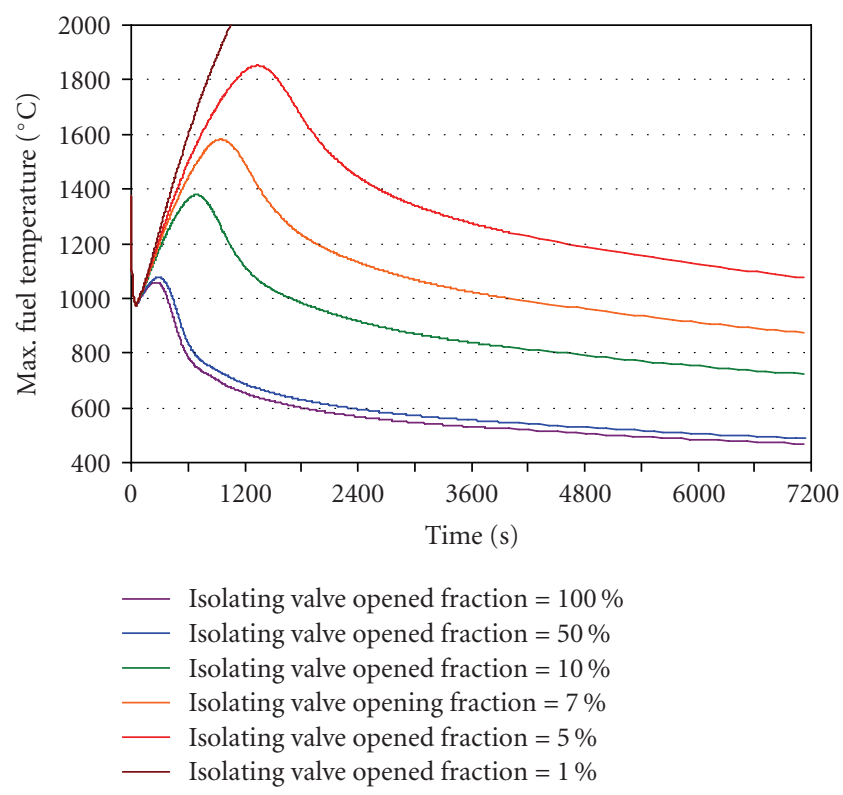

FIGURE 18: Maximum fuel temperature evolutions for different values of DHR valve stem position (1 DHR loop available).

outlet versus the additional singular pressure drop in the NC loop.

According to the results obtained in this sensitivity study, it was decided to perform another set of calculations for an additional singular pressure drop in the NC loop of about $10000 \mathrm{~Pa}$ (i.e., valve opening fraction close to $7 \%$ ). The RMPS methodology was applied with the same set of values for critical parameters as generated by LHS in the RMPS reference case. The temperature evolutions with time are reported in Figure 20.

In Table 5 are given the statistical results of the responses provided by the CATHARE 2 calculations.

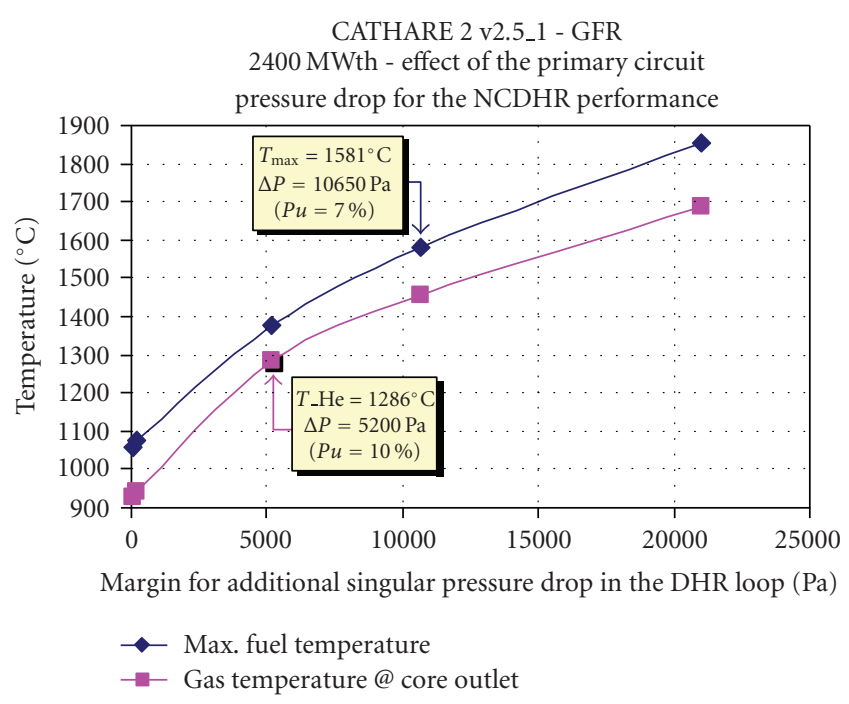

FIGURE 19: Fuel and gas temperature evolutions versus additional pressure drop in the DHR loop.

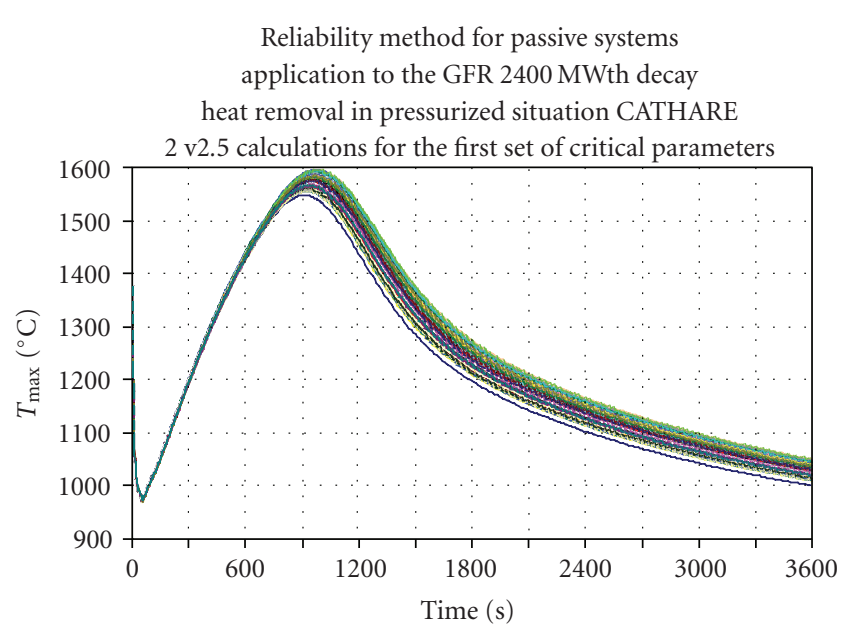

FIGURE 20: RMPS alternative case (1 DHR loop, valve opening fraction $=7 \%$ ).

TABLE 5: Results for the RMPS alternative case.

\begin{tabular}{lcccc}
\hline & Mean & SD & Lower & Upper \\
\hline TMAX $\left({ }^{\circ} \mathrm{C}\right)$ & 1575 & 10.09 & 1547 & 1595 \\
TUPPER $\left({ }^{\circ} \mathrm{C}\right)$ & 1451 & 6.81 & 1434 & 1465 \\
\hline
\end{tabular}

As in the reference case, a linear correlation has been determined in order to increase the number of calculations (up to $10^{6}$ ) and correlatively, the statistics precision for the NC reliability evaluation. Considering a pressure loss penalty of about $0.1 \mathrm{MPa}$, the unreliability of the NC process is evaluated at about $2,3,10^{-3}$ considering only the TMAX criterion. The most influent parameters for the NC performance and reliability are the same as in the reference case (i.e., T2DHR, FRPLAQ, and REPLAQ). 


\section{CONCLUSIONS AND IMPACT FOR THE GFR DESIGN AND PROBABILISTIC ENGINEERING ASSESSMENT}

In the frame of the ongoing probabilistic safety assessment in support to the 2400 MWth GFR design (called "probabilistic engineering assessment"), the RMPS methodology has been applied in order to assess the performance and the reliability of the natural circulation DHR in pressurized situations (i.e., for intact helium pressure boundary). So far, the gaseous NC process is foreseen:

(i) for pressurized situations in the early phase (i.e., first 24 hours) of transients characterized by the integrity of primary circuit;

(ii) for the transient termination (here called "late phase," starting around one day after the initiating event) of depressurized situations.

Owing to the DHR system features (dedicated loops for forced or natural circulation of gas, with passive water-filled secondary circuit), the primary gaseous coolant NC performance is directly related to the natural circulation capability in the secondary side pressurized water circuit, which is thermally linked to a ternary pool. Then, the frame of RMPS exercise for the GFR DHR system is involving a "two-inone" exercise: one for gaseous coolant, the second for pressurized water natural circulation. This interdependency of physical processes had lead to a methodology proposal in order to define the critical parameters for the RMPS exercise. This proposal is to determine the critical parameters according to "engineering judgment" based on a simplified "deductive analysis" (or cause-consequence analysis). Two classes of critical parameters were determined for the pressurized situation: the first addresses the specific uncertainties associated with factors on which the magnitude of the engaged forces and counter forces depends (values of heat transfer coefficients and pressure losses), where the second relates to uncertainties associated with the potential discrepancy of T-H parameters at "transient" initiation.

Correlatively, sensitivity studies were performed with the CATHARE 2 code to check the influence of the time delay before the forced circulation is lost (FC being the first line of defense) on T-H conditions at NC actuation. The results obtained are exhibiting that the core decay heat and primary pressure levels at NCDHR actuation do not appear as critical parameters for the reliability and performance assessment of this passive system. Translated for the GFR PEA, it validates the event representation in a Boolean model, as all active systems failures during the first 24 hours are aggregated as they occur at initiating event ("static" probabilistic model).

Owing to the precision required for this first NCDHR performance and reliability assessment and compared to the magnitude of other sources of uncertainties in the PEA model, the number of calculations is first limited at 100 . However, a linear correlation between TMAX and input parameters, and based only on 6 input parameters, has been determined. The linear standard regression coefficients were applied in order to rank the most influent parameters. For the maximum temperature of materials in the core region, the most influent parameters are according to importance:

(i) FRPLAQ (multiplicative factor for laminar NC pressure drop in the core region);

(ii) REPLAQ (Reynolds number for turbulent to laminar transition in the core region);

(iii) T2DHR (ternary pool and secondary circuit temperature level at DHR initiation).

Compared to the failure/success criteria fixed at $1600^{\circ} \mathrm{C}$ as mentioned earlier in this document, the results obtained with the CATHARE 2 code are exhibiting the safety margin conferred by the DHR loop structural and thermodynamical design. According to the above-mentioned linear regression, $10^{6}$ simulations were performed to increase the number of calculations (compared to the 100 ones performed with CATHARE 2) and then to improve the probability value of the NC reliability assessment in the PEA model. The results are providing an NCDHR unreliability upper bounded by $5 \cdot 10^{-6}$ for the reference case. This result should be regarded knowing that previous parametric studies on the NCDHR reliability value in the GFR PEA model (from $10^{-1}$, as reference value, to 0 ) were leading to a weak reduction of the core damage frequency of about 3\% (for the initiating event families retained for this first model and according to the assumption that the same level of NCDHR reliability will be obtained for depressurized situations).

On the other hand, the sensitivity study performed upon the additional singular pressure drop in the NC loop (through the DHR system isolating valve opening fraction) exhibits that the process unreliability ranges from $5 \cdot 10^{-6}$ (reference) to $2,3 \cdot 10^{-3}$ ( $\Delta P \approx 0.1 \mathrm{MPa}$ ) in pressurized situations. At this stage, it should be mentioned that the valve opening fraction was not retained as critical parameter (i.e., with distribution attached on this parameter) due first to its influence on temperature results (potentially masking the effects of others parameters) and also in relation with the common practice in PSA, in which partially opened valves are not depicted. These results should be weighted against the mean reliability value of an active system which is near $10^{-3}$.

Nevertheless, the effect of additional pressure drop in the NC loop may be translated to insights for reactor design team and is potentially combining a broad range of uncertainties. Indeed, as the GFR design is still in progress, the improvements of the concept and of specific components (DHR heat exchanger, core) may lead to a reduction of margin compared to the present design. In addition, the CATHARE 2 model for GFR, even detailed, is not representing all the sources of counter forces potentially challenging the NC process. Then, for the design team, it defines margin for overall pressure drop increase in the primary NC loop. Another way to interpret this result could be linked to a reliability allocation for the NCDHR process in order to guaranty a defined core damage frequency. Then, it fixes the overall NC loop pressure drop potential in order to respect the, to date, success/failure criteria.

The pursuit of this work is now related to the study of depressurized situations where the primary circuit is linked 
to the guard containment and to $\mathrm{T}-\mathrm{H}$ involved in it (natural leakage, exchange with a large amount of structures, etc.).

\section{NOMENCLATURE}

$f$ : Friction factor;

Re: Reynolds number;

Nu: Nusselt number;

Pr: Prandtl number;

Cv: Valve flow Coefficient;

$\mathrm{Pu}$ : Stem position for a valve;

$q$ : Mass flow in $\mathrm{kg} / \mathrm{s}$;

$P_{\mathrm{a}}$ : Upstream pressure in $\mathrm{Pa}$;

$\rho_{\mathrm{a}}$ : Upstream gas density.

\section{ACKNOWLEDGMENTS}

This work is part of the Risk Control Domain work program of the Nuclear Development and Innovation Division inside the CEA/Nuclear Energy Directorate. The authors thank all contributors, namely, B. Iooss, F. Bertrand, N. Perot, N. Devictor from CEA/Directorate of Nuclear Energy, and M. Balmain from Electricité de France.

\section{REFERENCES}

[1] N. Devictor, P. Saignes, B. Mathieu, A. Bassi, and F. Bertrand, "CEA program of work to carry out a level 1 PSA on the gascooled fast reactor," in Proceedings of the American Nuclear Society International Topical Meeting on Probabilistic Safety Analysis (PSA '05), vol. 2005, pp. 289-294, San Francisco, Calif, USA, September 2005.

[2] J. C. Garnier, C. Bassi, M. Blanc, et al., "Contribution to GFR design option selection," in Proceedings of the International Congress on Advances in Nuclear Power Plants (ICAPP '06), pp. 560-568, Reno, Nev, USA, June 2006.

[3] J. C. Garnier, P. Dumaz, N. Chauvin, and A. Ravenet, "Status of GFR pre-conceptual design study," in Proceedings of the International Congress on Advances in Nuclear Power Plants (ICAPP '07), Nice, France, May 2007.

[4] J. Y. Malo, C. Bassi, T. Cadiou, et al., "The DHR systems of the GFR, preliminary design and thermal-hydraulic studies," in Proceedings of the International Congress on Advances in Nuclear Power Plants (ICAPP '05), vol. 2, pp. 965-974, Seoul, South Korea, May 2005.

[5] M. Marquès, J. F. Pignatel, P. Saignes, et al., "Methodology for the reliability evaluation of a passive system and its integration into a probabilistic safety assessment," Nuclear Engineering and Design, vol. 235, no. 24, pp. 2612-2631, 2005.

[6] L. P. Pagani, G. E. Apostolakis, and P. Hejzlar, "The impact of uncertainties on the performance of passive systems," Nuclear Technology, vol. 149, no. 2, pp. 129-140, 2005.

[7] F. J. Mackay, G. E. Apostolakis, and P. Hejzlar, "Incorporating reliability analysis into the design of passive cooling systems with an application to a gas-cooled reactor," Nuclear Engineering and Design, vol. 238, no. 1, pp. 217-228, 2008.

[8] P. Saignes, C. Bassi, P. Azria, N. Devictor, and M. Balmain, "The CEA 2400 GFR probabilistic engineering assessment," Transactions of the American Nuclear Society, vol. 96, pp. 233 234, 2007.
[9] J. M. Reinert and G. E. Apostolakis, "Including model uncertainty in risk-informed decision making," Annals of Nuclear Energy, vol. 33, no. 4, pp. 354-369, 2006.

[10] Risk Spectrum, "RiskSpectrum ${ }^{\circledR}$ PSA Professional," Relcon Scandpower AB, www.riskspectrum.com.

[11] V. Brun-Magaud, et al., "Calcul de la puissance résiduelle de l'assemblage central et du cur de référence 2004 RNR-G à plaques pour des temps courts," CEA report-DER/SPRC/ LEDC/DO-93, 2005.

[12] M. Farvacque, M. Robert, M. Parent, and B. Faydide, "CATHARE 2 v2.5 : a fully validated CATHARE version for various applications," in Proceedings of the 10th International Topical Meeting on Nuclear Reactor Thermal Hydraulics (NURETH '03), Seoul, South Korea, October 2003.

[13] O. Widlund, G. Geffraye, F. Bentivoglio, et al., "Overview of gas-cooled reactors applications with CATHARE," in Proceedings of the 11th International Topical Meeting on Nuclear Reactor Thermal Hydraulics (NURETH '05), Avignon, France, October 2005.

[14] F. Bentivoglio, et al., "The CATHARE simulation of non depressurised transients for the $2400 \mathrm{MWth}$ gas fast reactor concept," in Proceedings of the International Congress on Advances in Nuclear Power Plants (ICAPP '07), Nice, France, May 2007.

[15] M. Berthoux, "Recommandations pour évaluer le frottement et l'échange de chaleur lors des études de conception des réacteurs à plaques de la filière RNR-G," CEA reportDER/SSTH/LIEX/2007-021, 2007. 

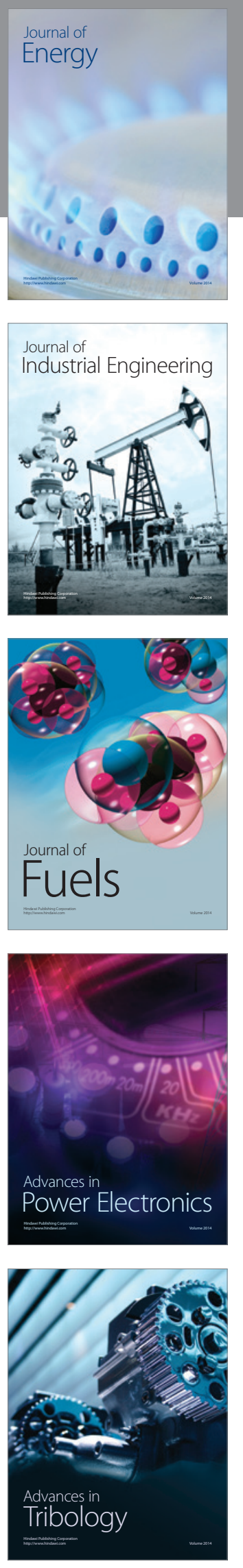
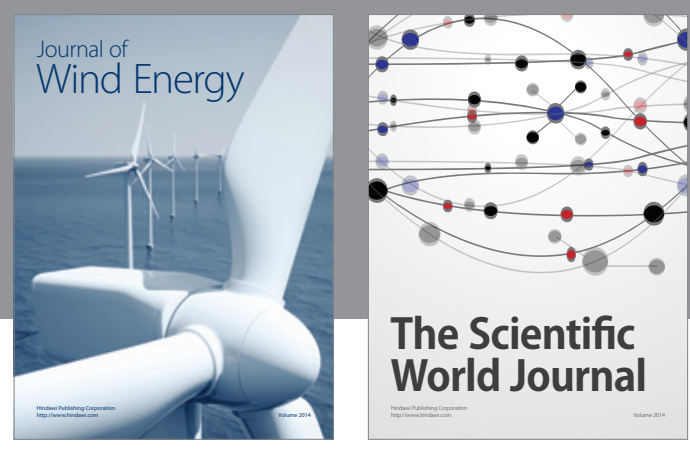

The Scientific World Journal

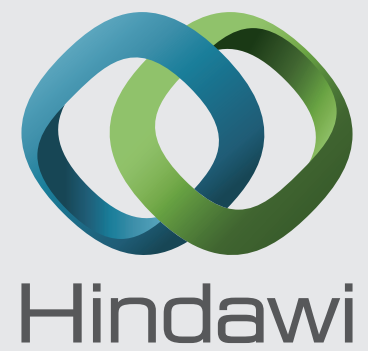

Submit your manuscripts at http://www.hindawi.com
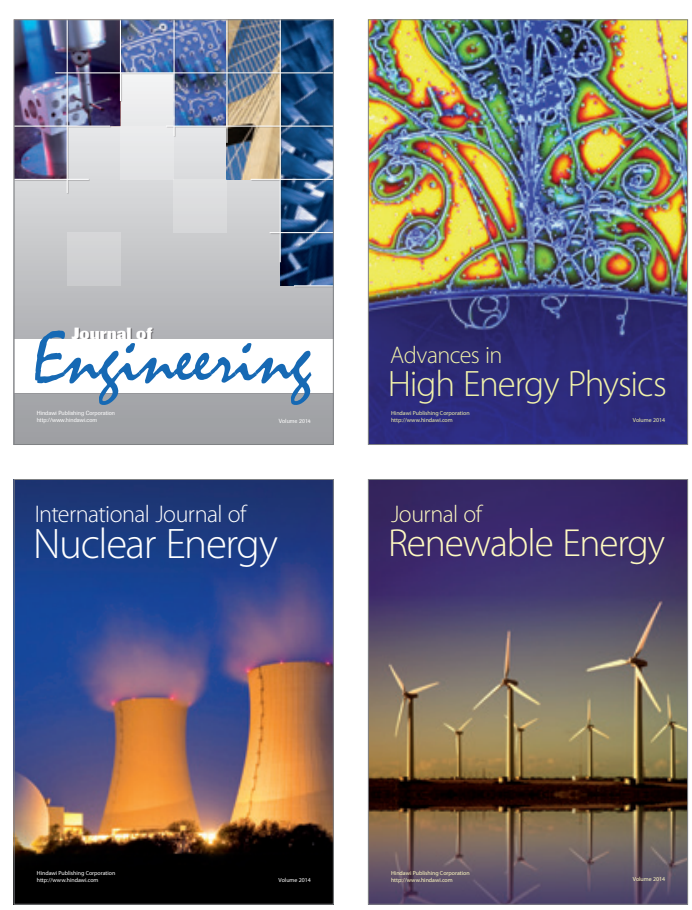

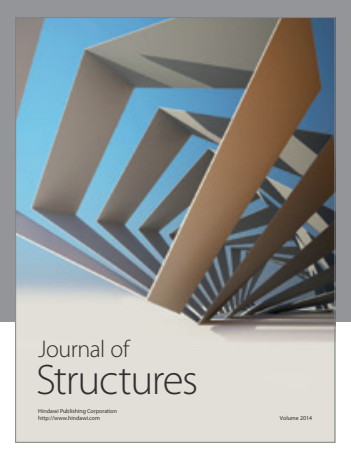

Rotating
Mechinery
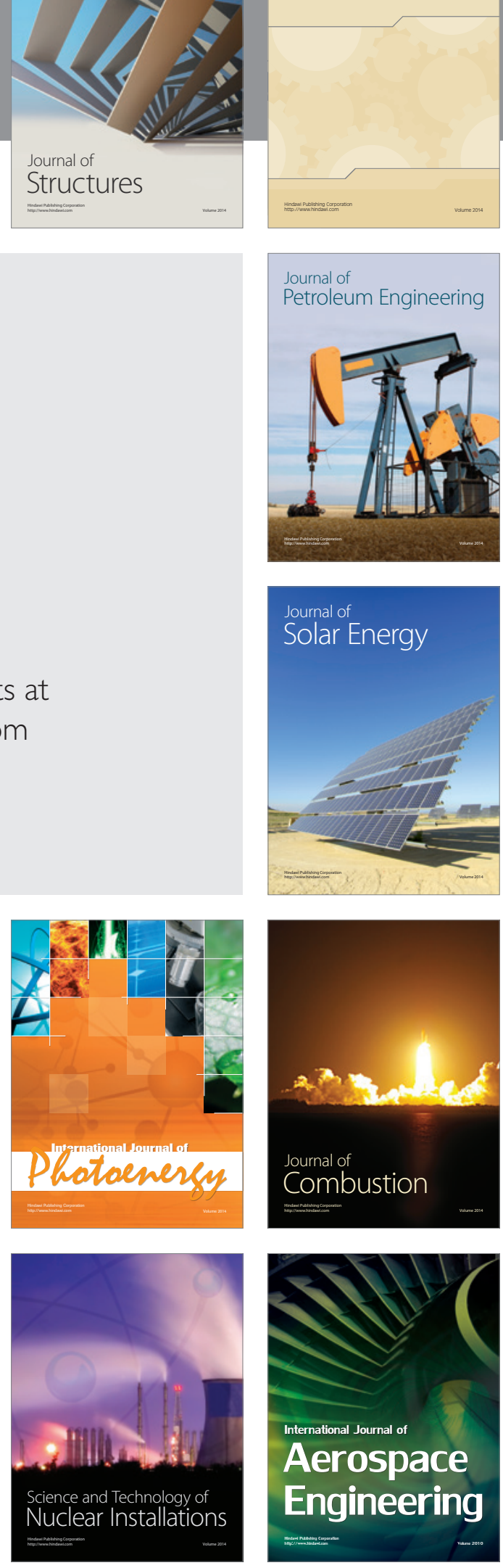